\title{
On the influence of wind and waves on underwater irradiance fluctuations
}

\author{
M. Hieronymi ${ }^{1,2,3}$ and A. Macke ${ }^{1}$ \\ ${ }^{1}$ Leibniz Institute for Tropospheric Research (IFT), Leipzig, Germany \\ ${ }^{2}$ Helmholtz Centre for Ocean Research (GEOMAR), Kiel, Germany \\ ${ }^{3}$ Institute of Coastal Research, Helmholtz Centre Geesthacht (HZG), Germany \\ Correspondence to: M. Hieronymi (martin.hieronymi@hzg.de)
}

Received: 1 March 2012 - Published in Ocean Sci. Discuss.: 20 March 2012

Revised: 29 May 2012 - Accepted: 11 June 2012 - Published: 10 July 2012

\begin{abstract}
The influence of various wind and wave conditions on the variability of downwelling irradiance $E_{\mathrm{d}}(490 \mathrm{~nm})$ in water is subject of this study. The work is based on a two-dimensional Monte Carlo radiative transfer model with high spatial resolution. The model assumes conditions that are ideal for wave focusing, thus simulation results reveal the upper limit for light fluctuations. Local wind primarily determines the steepness of capillary-gravity waves which in turn dominate the irradiance variability near the surface. Down to $3 \mathrm{~m}$ depth, maximum irradiance peaks that exceed the mean irradiance $\overline{E_{\mathrm{d}}}$ by a factor of more than 7 can be observed at low wind speeds up to $5 \mathrm{~m} \mathrm{~s}^{-1}$. The strength of irradiance fluctuations can be even amplified under the influence of higher ultra-gravity waves; thereby peaks can exceed $11 \overline{E_{\mathrm{d}}}$. Sea states influence the light field much deeper; gravity waves can cause considerable irradiance variability even at $100 \mathrm{~m}$ depth. The simulation results show that under realistic conditions $50 \%$ radiative enhancements compared to the mean can still occur at $30 \mathrm{~m}$ depth. At greater depths, the underwater light variability depends on the wave steepness of the characteristic wave of a sea state; steeper waves cause stronger light fluctuations.
\end{abstract}

\section{Introduction}

The solar radiative transfer into the ocean is strongly influenced by air-sea interactions. Wind generates waves at the free water surface that can range in size from small ripples, so called capillary waves, to huge waves over $25 \mathrm{~m}$ height (e.g. Sterl and Caires, 2005). The wind strength, the areal and temporal wind impact, and the water depth influence the formation of a wind sea. Sunlight is refracted at the irregularly shaped water surface. Individual waves that are superposed at the surface can act as lenses that focus the light at various water depths. For this reason, the underwater light field, in this work characterized by the downwelling irradiance, is subject to considerable variance that characteristically depends on the surface waves and thus on the prevailing wind condition and the sea state.

Besides the mentioned wave conditions, underwater light fluctuations also depend on the spectral range of sunlight, the sun altitude, diffuse sky radiation, clouds, and on the inherent optical properties (IOPs) of the water (e.g. Stramski, 1986; Walker, 1994; Stramska and Dickey, 1998; Gernez and Antoine, 2009; Gege and Pinnel, 2011). Compared to other natural light regimes (e.g. in a forest), the variability of irradiance in water can be very large, e.g. near the surface irradiance peaks can exceed the time-averaged irradiance by a factor of 15 (Darecki et al., 2011).

The generation mechanisms of irradiance fluctuations and their decreasing intensity with increasing water depth are known (e.g. Schenck, 1957; Snyder and Dera, 1970; Nikolayev and Khulapov, 1976; Stramski and Dera, 1988; Gernez et al., 2011). Whereas, less is known about the winddependency of light fluctuations and very little is known about its sea state dependency. There are several papers on the relationship between wind conditions and underwater light field fluctuations (e.g. Nikolayev et al., 1972; Dera and Stramski, 1986; Gernez and Antoine, 2009; Weber, 2010; Hieronymi and Macke, 2010; Darecki et al., 2011). The general view is that the most favorable conditions for light 
focusing by waves prevail at light to moderate winds between 2 and $7 \mathrm{~m} \mathrm{~s}^{-1}$. With this work we will show that other wind and wave conditions also can lead to extreme irradiance fluctuations, in particular if we look at different water depths. We provide the first detailed analysis on the influence of local wind on the light variability in the near-surface layer, and in addition on the impact of fully developed sea states, on the light regime within the upper ocean mixed layer down to $100 \mathrm{~m}$ depth.

Our work is based on a two-dimensional Monte Carlo model (Hieronymi et al., 2012) whose capability has been verified by in-situ measurements of the underwater light field and by inter-comparison with the widely-used radiative transfer code HydroLight (Mobley, 1994). The model is especially intended for investigations of spatially high resolved light fields underneath any desired wave profiles.

\section{Applied methods}

\subsection{Radiative transfer models}

The radiative transfer in water is simulated by means of two model approaches that are explained in detail by Hieronymi et al. (2012). At small depths, the underwater light regime is governed by high-frequency and small-scale intensity changes (e.g. Snyder and Dera, 1970; Hieronymi and Macke, 2010; Darecki et al., 2011). For this reason, we choose a high spatial resolution of $d x=2.5 \mathrm{~mm}$ for our nearsurface model; some current irradiance collectors have sensor head diameters of $2.5 \mathrm{~mm}$ (e.g. Darecki et al., 2011). In very clear seawater the fraction of total downwelling irradiance due to scattering in the first metres of the water body is small compared to the direct light beam and, furthermore, most of this scattered light is located very close to the initial light path because of the predominance of the forward scattering (Hieronymi, 2011). Thus, we neglect the diffuse light in our near-surface model (which is valid down to approximately $5 \mathrm{~m}$ ) and just superpose narrow single rays according to the wave geometry. This approach has been used several times for example by Schenck (1957), Nikolayev et al. (1972), Stramski and Dera (1988), or Zaneveld et al. (2001). In our model, the intensity of each single ray is continuously attenuated by absorption of the medium.

The second model approach is designated for larger water depths down to $100 \mathrm{~m}$, where light scattering is not negligible. In this model, the spatial expansion and attenuation of single light beams is simulated on the basis of a Monte Carlo method (Hieronymi, 2011). The used model resolution is $10 \mathrm{~cm}$ horizontally and vertically.

\subsubsection{Model input parameters}

The model input parameters are listed in Table 1. They are selected in such a manner that maximum light fluctuations can be achieved (Dera and Stramski, 1986; Walker,
Table 1. Underlying data for radiative transfer simulations.

\begin{tabular}{llll}
\hline Wavelength of light & $\lambda$ & {$[\mathrm{nm}]$} & 490 \\
\hline Sun zenith angle & $\theta_{\mathrm{s}}$ & {$\left[{ }^{\circ}\right]$} & 0 \\
\hline Refractive index of seawater & $n$ & {$[-]$} & 1.34 \\
\hline Fraction of diffuse sky & Dif & {$[\%]$} & 10 \\
\hline Chlorophyll $a$ concentration & $\mathrm{Chl}$ & {$\left[\mathrm{mg} \mathrm{m}^{-3}\right]$} & 0.1 \\
\hline
\end{tabular}

1994; Gernez and Antoine, 2009). The radiative transfer is calculated for a single wavelength of $490 \mathrm{~nm}$, which can be considered representative for the blue-green spectral band. Light of this spectral range can penetrate especially deep into oligotrophic waters. Different measurements have shown a wavelength-dependency of light fluctuations in shallow water (e.g. Gernez and Antoine, 2009; Darecki et al., 2011; Gege and Pinnel, 2011). However, orange-red light $(580-700 \mathrm{~nm})$ is strongly attenuated by absorption in water (e.g. Zielinski et al., 2002). Below $10 \mathrm{~m}$ water depth, the blue-green spectral components yield the vast majority of the photosynthetically active radiation (PAR) $(400-700 \mathrm{~nm})$. For this reason, we assume that the fluctuation characteristics at $490 \mathrm{~nm}$ can be considered representative for the variability of the entire PAR value.

The presented simulations are carried out for perpendicular solar irradiation and for an extreme clear atmosphere, where the diffuse skylight due to atmospheric Rayleigh and Mie scattering accounts for $10 \%$ only (the sky illumination is assumed to be isotropic). The water body under consideration is very clear and oligotrophic; the (wavelengthdepending) inherent optical properties of the well-mixed seawater are derived from a chlorophyll $a$ concentration $\mathrm{Chl}$ of $0.1 \mathrm{mg} \mathrm{m}^{-3}$ (Morel et al., 2007; Morel, 2009). The resulting diffuse attenuation coefficient for the downward irradiance $K_{\mathrm{d}}(490 \mathrm{~nm})$ is approximately $0.038 \mathrm{~m}^{-1}$, relating to a flat sea surface.

\subsection{Description of the sea surface}

For generating two-dimensional irregular wave profiles, we apply the superposition principle of solitary sine waves, whose amplitudes are determined by the omnidirectional elevation spectrum. First, consideration is given to the effects of locally limited wind. The wind friction velocity basically defines the steepness of short waves of less than about a half metre length. In particular capillary and capillary-gravity waves in the wavelength $(L)$ range of $0.7-3 \mathrm{~cm}$ are most affected by the wind friction (Jähne and Riemer, 1990). We use the wave spectrum as it is proposed by Elfouhaily et al. (1997)

$S(k)=k^{-3}\left[B_{\mathrm{LW}}+B_{\mathrm{SW}}\right]$, 


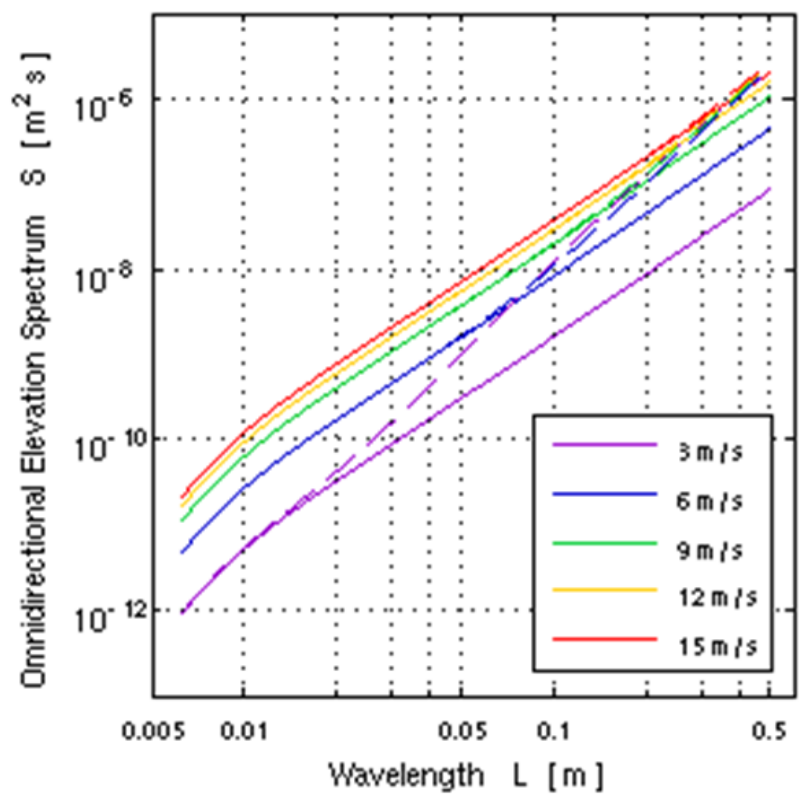

Fig. 1. Wave spectra for different local wind conditions that are used for our near-surface underwater light field simulations (short-wave part only); the dashed lines show the modification due to the longwave part of the unified spectra.

where $k$ is the angular wavenumber $(=2 \pi / \mathrm{L})$, subscripts LW and SW indicate the long- and short-wave frequencies, and $B$ stands for the curvature spectra. In order to straightforwardly distinguish the pure wind effects on the light field, we first use the short-wave part of the spectrum only. The spectra apply for a minimum wind speed of $3 \mathrm{~m} \mathrm{~s}^{-1}$. Figure 1 shows the utilized elevation spectra for wind speeds $U_{10}(10 \mathrm{~m}$ above the sea level) from 3 to $15 \mathrm{~m} \mathrm{~s}^{-1}$ (solid lines). The corresponding curvature spectra exhibit a gravity-capillary peak at $1.7 \mathrm{~cm}$ wavelength for all wind speeds. With increasing wind, the spectra move together. This implies that the wave profiles that are generated out of the spectra (with random phase position) have almost the same statistical characteristics with strong wind, and thus the corresponding light fields must be very similar.

In the open ocean, fetch normally is not limited; windwaves can grow to fully developed seas. The dashed lines in Fig. 1 represent the total spectra (Eq. 1), where both, longand short-wave, regimes are considered (for fully developed seas). In particular at lower wind speeds, the unified longand short-wave spectra adapt to the high-wind spectra with increasing wavelength. In case of weak wind over an unlimited fetch, ultra-gravity waves $(>2 \mathrm{~cm})$ have actually higher amplitudes compared to a restricted fetch, which has to do with the wave growth and the so called wave age. We bear this long-wave interaction in mind, but we primarily use the short-wave part of the spectra (solid lines) and apply this to waves of $6 \mathrm{~mm}$ to $50 \mathrm{~cm}$ length. We suggest that this spec- tral range is directly associated with the term "local wind", although wind in general can also originate much longer waves, as ordinary gravity waves or swell waves.

In a second step, the significance of distinctive sea states is considered. Sea states are characterized by the significant wave height $H_{\mathrm{s}}$ and by a mean wave period $T$. Figure 2 (left) shows combinations of wave height and period together with the prevailing averaged wind speed $U_{10}$ as it appears in the global ocean. The data are derived from the KNMI/ERA40 wave atlas (Sterl and Caires, 2005). The corresponding wavelength $L$ is additionally marked at the top of the chart. It is deduced from the dispersion relation for deep-water waves (Airy wave theory):

$L=\frac{g}{2 \pi} T^{2}$,

in which $g$ is the acceleration of gravity. The ratio of wave height to length $H / L$ is the wave steepness, which is theoretically 0.14 at maximum; steeper waves break. The white areas at the bottom left in both diagrams of Fig. 2 stand for waves too steep to occur in nature (i.e. they are not in the wave atlas); these wave combinations are not considered in this study. Sea states with wave periods longer than $11 \mathrm{~s}$ (about $190 \mathrm{~m}$ wave length) are not considered either, since they are rather insignificant in terms of underwater light field variability.

Figure 2 right shows the frequency of occurrence (probability density function $P D F$ ) of sea states in the global ocean (Sterl and Caires, 2005). Considerable differences arise in regional and monthly climatologies. In general, extremely steep seas occur rarely and wave systems with periods between 5 and $9 \mathrm{~s}$ and wave heights between 1 and $3 \mathrm{~m} \mathrm{oc}-$ cur most frequently (60\% of all cases). This range is framed white in the right diagram of Fig. 2.

With regard to the model assumption of homogeneous water properties, it should be mentioned that surface waves cause a mixing of the upper ocean layer. Simplistically, it can be assumed that the sea water within this layer has homogeneous physical and bio-optical properties. Beside the fact that marine phytoplankton needs sufficient light (supplied from above) as well as nutrients (supplied from below), the mixed layer depth MLD is an important factor associated with the accumulation of phytoplankton biomass and the development of deep chlorophyll $a$ maxima. In oligotrophic waters, where the surface mixed layer is poor in nutrients, chlorophyll $a$ maxima are often found between 20 and $150 \mathrm{~m}$ depth with maximum concentrations of generally 3 to 10 times of those in surface waters (e.g. Anderson, 1969; Cullen, 1982; Furuya, 1990; Zielinski et al., 2002; Huisman et al., 2006). The depth of mixing $z_{\text {MLD }}$ can be predicted based on the knowledge of the wave climate. According to Babanin (2006), the wave-induced MLD can be approximated by

$z_{\mathrm{MLD}}=\frac{g}{2 \omega^{2}} \ln \left(\frac{\alpha_{0}^{2} \omega}{R e_{\mathrm{cr}} v}\right)$, 


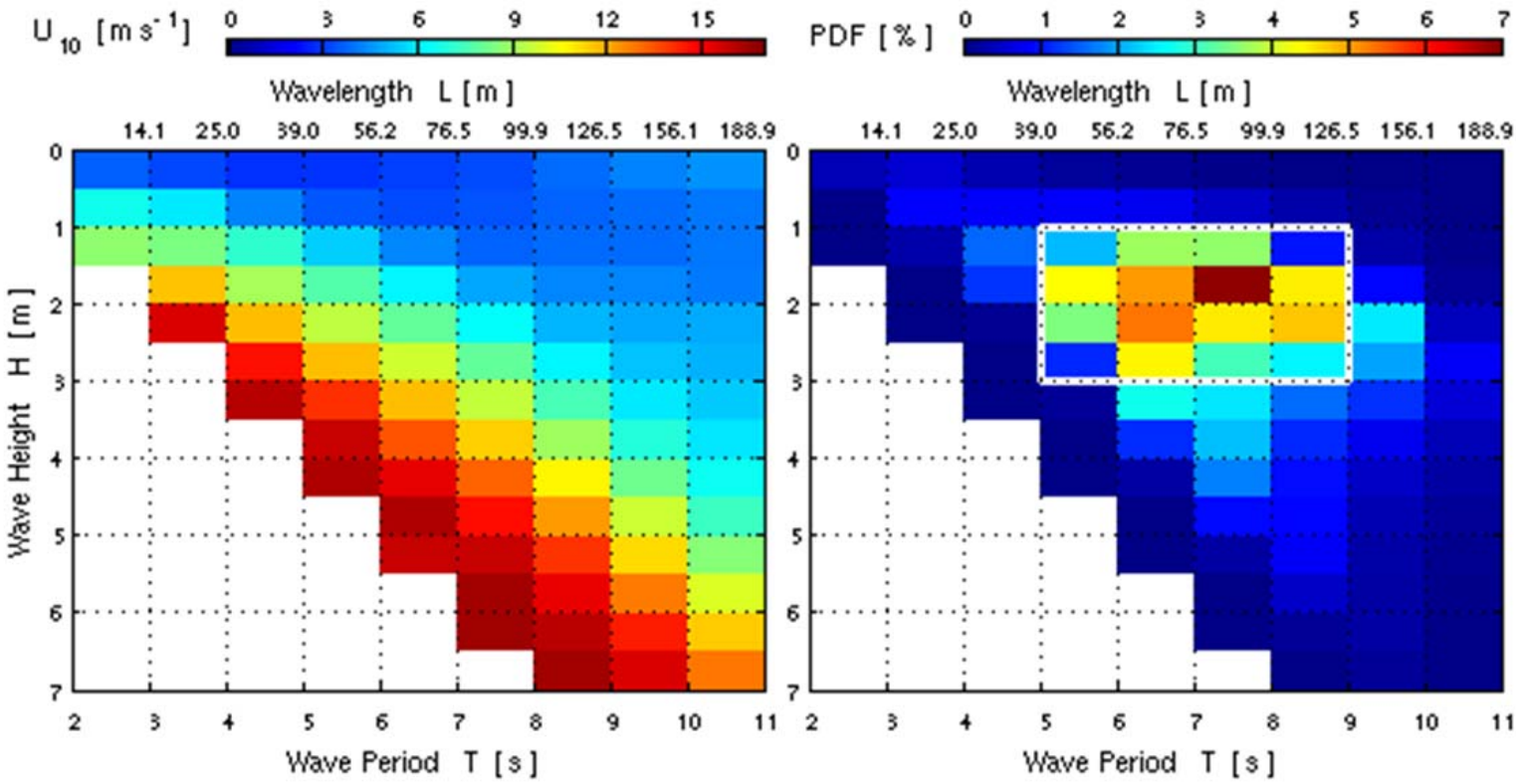

Fig. 2. Sea states under consideration for underwater light field simulations with $d x=10 \mathrm{~cm}$ horizontal resolution; left: input parameters (wave height $H$, wave period $T$, and wind speed $U_{10}$ ) for the generation of irregular wave profiles; right: probability of the occurrence of wave classes averaged over all seasons and regions (Sterl and Caires, 2005).

where $g$ is the acceleration of gravity, $\omega$ is the wave angular frequency, $a_{0}$ is the wave amplitude, $R e_{\mathrm{cr}}$ is the critical Reynolds number (chosen as $R e_{\mathrm{cr}}=3000$ ), and $v$ the kinematic viscosity of ocean water (chosen as $v=1.35 \cdot 10^{-6} \mathrm{~m}^{2} \mathrm{~s}^{-1}$ ). Figure 3 shows the mixed layer depth (Eq. 3) for the introduced wave classes. For a given wave period $z_{\text {MLD }}$ increases with growing wave height. The wave-induced upper ocean mixed layer can be more than $100 \mathrm{~m}$ deep. The figure provides an interesting hint to the depth of a deep chlorophyll $a$ maximum, which might be affected by deeply penetrating light fluctuations. In addition, an abrupt rise of biomass concentration is associated with a rapid change of the IOPs of the water body, i.e. the light beam attenuation (absorption and scattering) increases.

The irregular sea state profiles used in this work are generated by means of unified spectra for long and short waves over the full range of wavenumbers (Eq. 1). The wind-dependent high-frequency part is based on the work of Elfouhaily et al. (1997) (and their references). The colourcoding in Fig. 2 (left) shows the underlying "sea state typical" wind velocities $U_{10}$. We employ the two-parameter Pierson-Moskowitz spectrum for the respective long-wave regime as it is proposed by the International Towing Tank Conference (Pierson and Moskowitz, 1964; ITTC, 2002):

$S(f)=\frac{5 H_{\mathrm{S}}^{2}}{16 T_{P}^{4} f^{5}} \exp \left(-\frac{5}{T_{P}^{4} f^{4}}\right)$

where $f$ is the wave frequency, $H_{\mathrm{S}}$ is the significant wave height, and $T_{\mathrm{P}}$ is the spectral peak period. The two input pa-

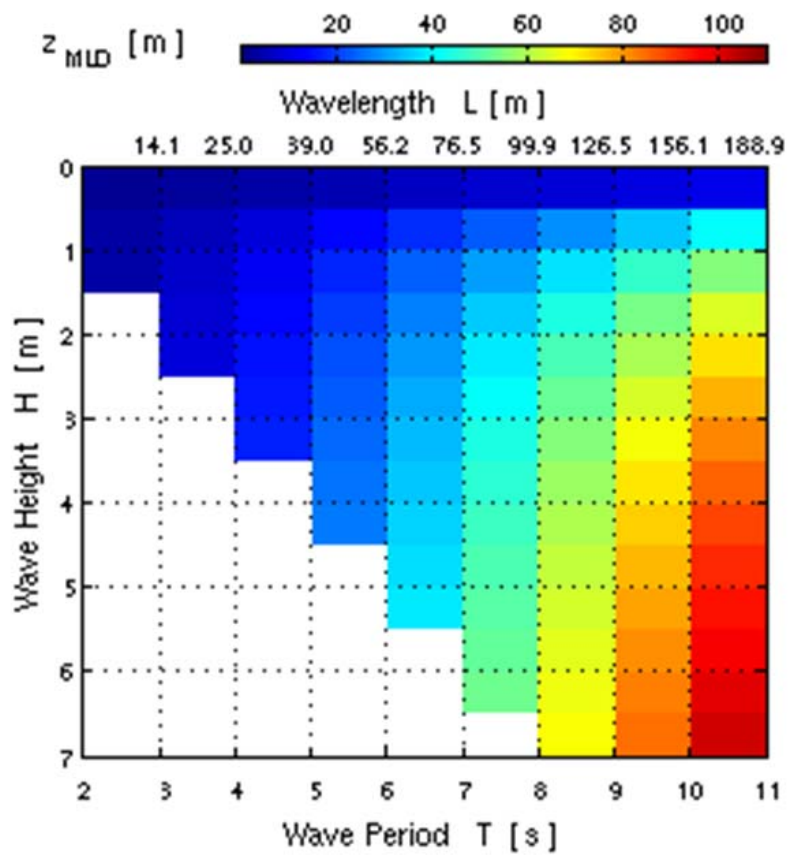

Fig. 3. Wave-induced mixed layer depth $z_{\text {MLD }}$ for the wave classes under consideration (Eq. 3).

rameters wave height and period (for ease without indices) are taken from Fig. 2 (left), where $H$ is 0.5 to $7 \mathrm{~m}$ and $T$ is 3 to $11 \mathrm{~s}$, respectively. As seen in Fig. 2 (left), different sea 
states can arise from equal prevailing wind velocities, which is due to different stages of wave growth, wave energy dissipation, or due to superposition of different wave systems. In some cases, especially in low-wind situations, the transition between short and long wave spectra can be subject to a discontinuity. This particularly applies to the range of small gravity waves, which are not unimportant in the context of subsurface light variability. The issue is addressed by insertion of an intermediate function into the spectrum that approximately fits to observations (e.g. Leykin and Rozenberg, 1984; Donelan et al., 1985; Jähne and Riemer, 1990).

All wave profiles under consideration are $600 \mathrm{~m}$ long with a horizontal resolution $d x$ of $0.1 \mathrm{~mm}$. The corresponding modelled wave slopes are always normally distributed due to the superposition of stochastic independent elementary waves. Under realistic conditions, the steepness of capillary or capillary-gravity waves is modulated by longer waves in such way that the short waves are steeper, on average, when riding on the forward faces of the longer waves (LonguetHiggins, 1982). This observation explains the actual winddependency of the skewness of the wave slope distribution (Cox and Munk, 1954), which is not regarded in this work.

\subsection{Fluctuation parameters}

The variability of the downwelling irradiance $E_{\mathrm{d}}$ in water is based on spatial datasets with horizontal resolutions $d x$ of $2.5 \mathrm{~mm}$ and $10 \mathrm{~cm}$, respectively. The water depth $z$ is positive downwards, vertical deflections of the sea surface (around the mean waterline at $\mathrm{z}=0 \mathrm{~m}$ ) are treated exactly. The vertical length of a narrow water column is defined as reference or true water depth $z_{t}$; the following light field analysis refers to this reference depth.

Light fluctuations are commonly described by the coefficient of variation

$C V=100 \frac{\sigma_{E}}{\overline{E_{\mathrm{d}}}}$,

given as the percentage ratio of the standard deviation $\sigma_{E}$ and the averaged downwelling irradiance $\overline{E_{\mathrm{d}}}$ at the reference depth. $E_{\mathrm{d}}$ time series are typically normalized with the mean level irradiance in order to evaluate extreme values. The normalized downwelling irradiance (related to spatial $E_{\mathrm{d}}$ variability) is denoted as

$\chi=\frac{E_{\mathrm{d}}(x)}{\overline{E_{\mathrm{d}}}}$.

Irradiance pulses that exceed the mean irradiance by a factor $\chi$ of more than 1.5 are termed underwater light flashes (Dera and Stramski, 1986). We define extreme values by means of the maximum normalized downwelling irradiance $\chi_{\max }$ and by the "significant irradiance enhancement" $\chi_{1 / 10}$. The latter describes the mean of the $10 \%$ highest irradiance values; the labelling is motivated by the definition of the significant wave height $H_{\mathrm{s}}$ (or $H_{1 / 3}$ ), which is the average height of the one-third highest waves. On the one hand, the significant irradiance enhancement provides a statistically smoothed function of extreme intensity peaks over the water depth; on the other hand, $\chi_{1 / 10}$ can be seen as a rough estimate for measured $E_{\mathrm{d}}$ maximum values, taking into account that the sampling rates of some radiometers may be insufficient for high-frequency irradiance measurements and that sensor integration times can elongate with increasing water depth (we did $E_{\mathrm{d}}$ measurements with a RAMSES-ACC-VIS radiometer (TriOS, Germany) with a spectral range of 320 to $950 \mathrm{~nm}$ and effective sampling rates of 2 to $8 \mathrm{~s}$ (Hieronymi et al., 2012)).

The modelled spatial light fluctuations are subject to a wavenumber analysis (analogous to frequency analysis) in order to characterize the statistical dynamics of the underwater light field and thereby draw conclusions on the influence of associated wave regimes at the sea surface. The power spectral density of $\chi$-fluctuations (variance spectrum) is computed by means of a fast Fourier transformation. The spectral peak length $L_{\mathrm{p}}$ marks the wavelength that contributes most to the variance. Nevertheless, an accurate determination of $L_{\mathrm{p}}$ is difficult for example in cases with a broad spectral maximum or if individual peaks are located in close vicinity. We therefore additionally use the mean (wave-) length of fluctuations $L_{\mathrm{m}}$ which comprises more of the relevant spectral band. It is determined by using the $n$-th spectral moments

$m_{n}=\int_{0}^{\infty} k^{n} S \chi(k) d k$,

where $k$ is the (angular) wavenumber and $S_{\chi}(k)$ the spectral density of the $\chi$-profile. The mean fluctuation length is the area below the spectrum $m_{0}$ divided by the spectral center of gravity $m_{1}$

$L_{m}=\frac{m_{0}}{m_{1}}$.

\section{Results and discussion}

\subsection{Direct influence of local wind conditions}

The influence of spatially very limited, so called "local", wind on the underwater light field is accessed by using the near-surface model with $d x=2.5 \mathrm{~mm}$ horizontal resolution. The evaluated model domain is $5 \mathrm{~m}$ deep and $20 \mathrm{~m}$ wide. The implemented irregular wave profiles with random phase are generated from the short-wave spectra Eq. (1) that are shown in Fig. 1 (solid lines). Figure 4 shows two $1 \mathrm{~m}$ wide sections of resulting spatial $E_{\mathrm{d}}$ distributions for a "light breeze" and a "near gale" wind situations $\left(3\right.$ and $\left.15 \mathrm{~m} \mathrm{~s}^{-1}\right)$. The red colours indicate a radiative enhancement of more than $100 \%$ of the surface insolation which is caused by the wavefocusing; bluish colours stand for a reduction due to defocusing. Waves of the capillary and capillary-gravity range of 


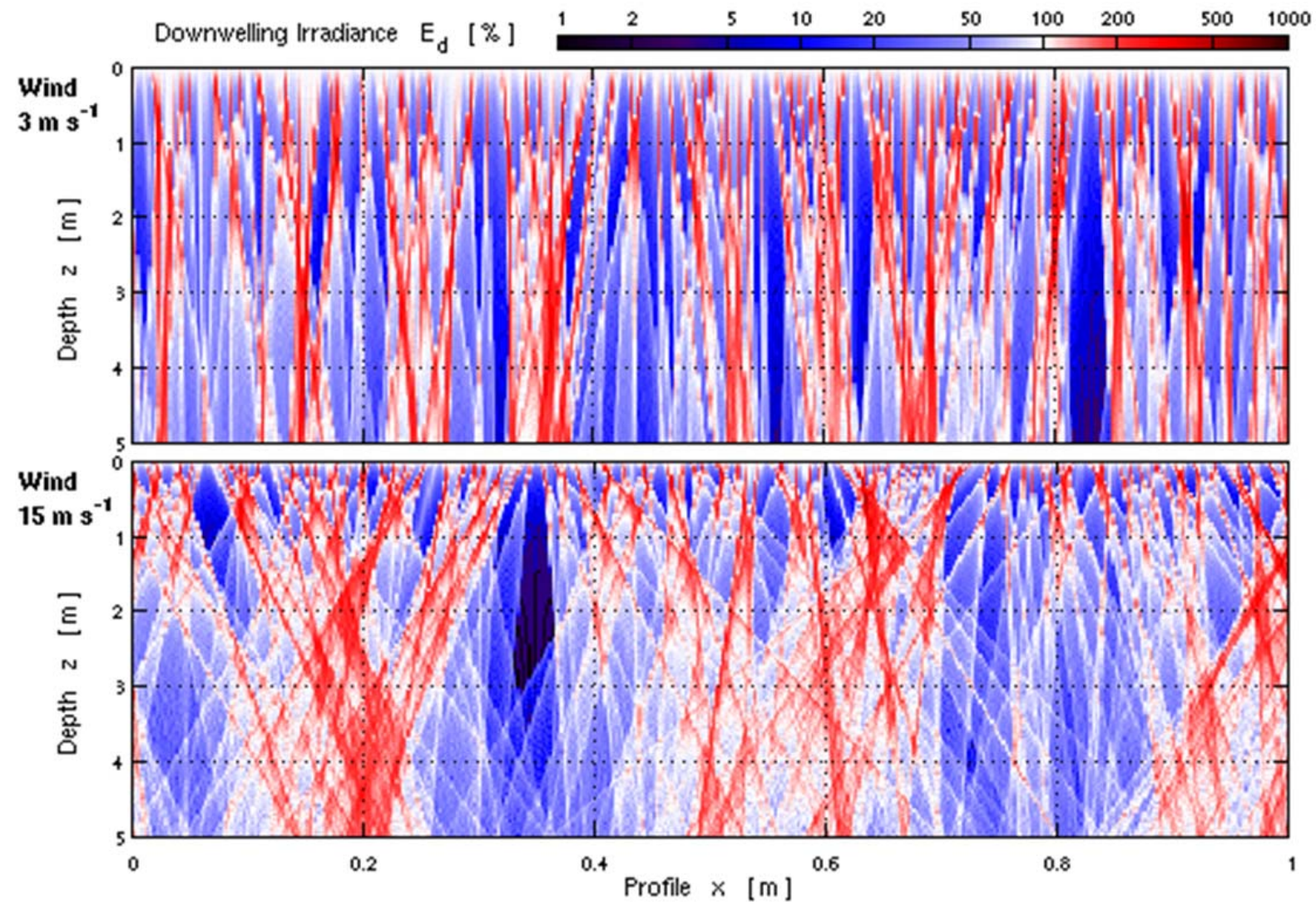

Fig. 4. Spatial distribution of the downwelling irradiance $E_{\mathrm{d}}$ due to local wind speeds of 3 and $15 \mathrm{~m} \mathrm{~s}^{-1}$ that are simulated with the nearsurface model with $d x=2.5 \mathrm{~mm}, E_{\mathrm{d}}$ above the surface is $100 \%$ (logarithmic colour scale).

$0.7-3 \mathrm{~cm}$ length play a key role in near-surface light focusing. Their spectral densities strongly increase with the wind friction velocity. In contrast, small gravity waves are less dependent on the local wind speed (Jähne and Riemer, 1990). Very close to the surface, the light field variance is dominated by the de-/focusing of waves in this order of magnitude, visible as clear stripes of $E_{\mathrm{d}}$ enhancements. Local wind determines the steepness of these waves, affecting the depth of the (first) focal point, i.e. the more wind, the closer the focal point comes to the surface. The red single rays are further deflected by overlaying small gravity waves, which again are steeper at stronger winds. This leads to intensified light beam grouping at different depths and together with the occurrence of secondary and further focal points that are caused by neighboring capillary-gravity waves, those larger waves are responsible for very intense irradiance fluctuations within the top $5 \mathrm{~m}$ layer. With increasing depth the narrow stripes of radiative concentration are geometrically scattered, light focusing is reduced, and in addition the intensity of each single ray is attenuated.

Some statistical characteristics of the two light fields (Fig. 4) are compared in Fig. 5. The occurrence frequencies of downwelling irradiance values are shown in Fig. 5a and $\mathrm{b}$. The mean values $\overline{E_{\mathrm{d}}}$ are almost identical, mainly because the surface albedo (i.e. irradiance reflectance) is wind-independent at high sun (Preisendorfer and Mobley, 1986); $\overline{E_{\mathrm{d}}}$ decreases exponentially with increasing water depth. However, one can clearly identify differences in the depth-dependence of the probability density functions $P D F$. Because of wave-focusing both probability distributions are highly skewed to the right and heavily tailed. The winddependent surface geometry affects the occurrence depth and intensity of extreme irradiance values. The $P D F$ skewness $\gamma_{1}$ is around 1.5 at depths between 0.5 and $2 \mathrm{~m}$ in the low wind situation, but only little more than 1 between 0.1 and $1.5 \mathrm{~m}$ depth in the case of strong wind. In both cases the excess kurtosis $\gamma_{2}$ can take maximum values of 3 , but $\gamma_{2}$ decays faster at strong wind, i.e. the probability distribution faster approaches a Gaussian shape and less variance results from extreme intensity peaks.

Figures $5 \mathrm{c}$ and $\mathrm{d}$ show the frequency of intensity peaks $N$ that exceed an irradiance level. In general, we see stronger and more frequently occurring irradiance peaks at low wind speed exceeding $7 \overline{E_{\mathrm{d}}}$ at the maximum. According to the model, light flashes of $6 \overline{E_{\mathrm{d}}}$ appear down to $5 \mathrm{~m}$ water depth 

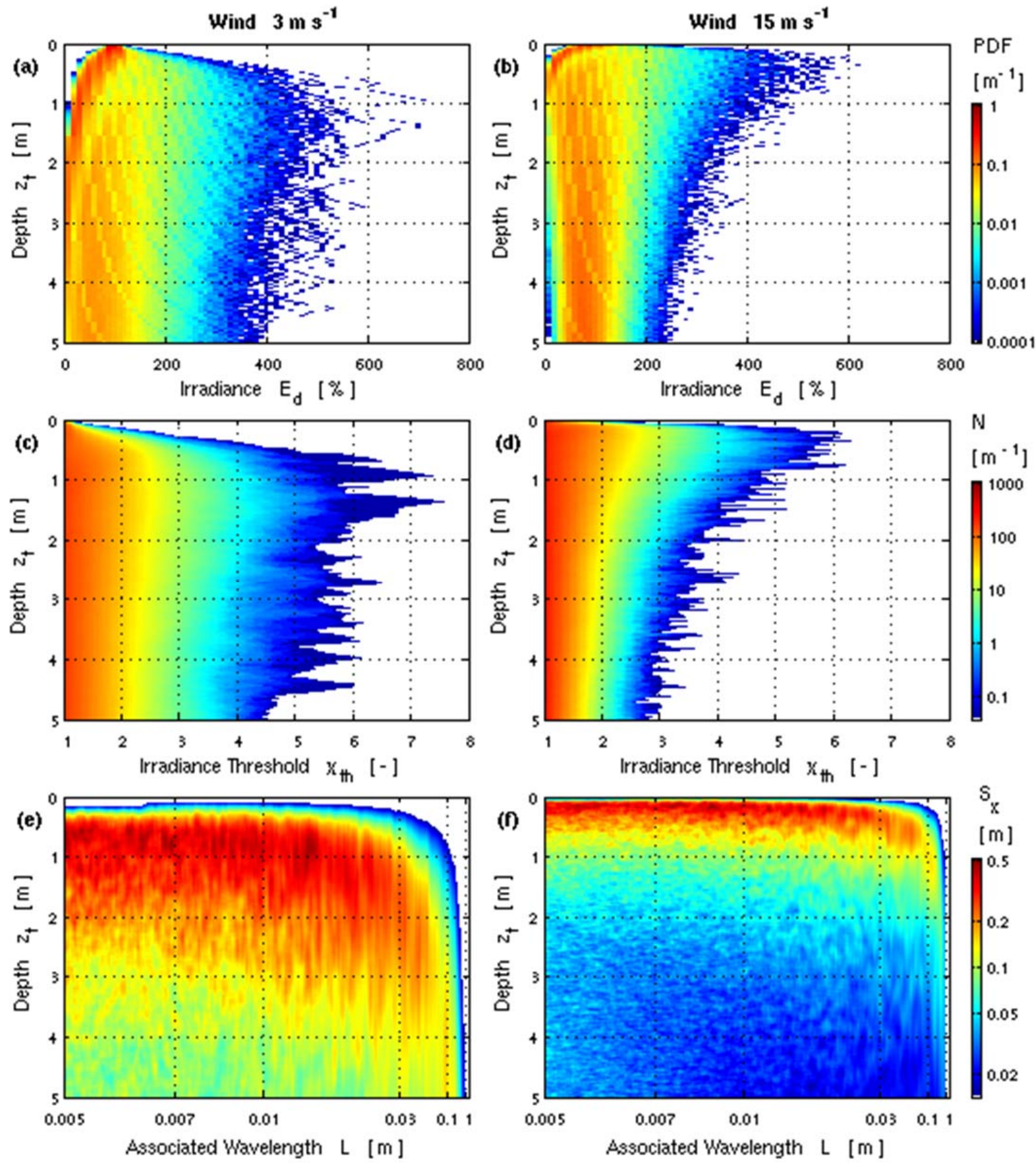

Fig. 5. Statistics of the underwater light fields from Fig. 4 with wind velocities of $3 \mathrm{~m} \mathrm{~s}^{-1}$ (left) and $15 \mathrm{~m} \mathrm{~s}^{-1}$ (right); top: probability density function $P D F$ of downwelling irradiance $E_{\mathrm{d}}$; middle row: number of flashes $N$ above a certain irradiance threshold $\chi_{t h}$; lower panels: power spectral density $S_{\chi}$ with respect to the normalized irradiance.

at moderate wind speeds, whereas the flash intensity is evidently reduced at the same depth at strong wind.

The corresponding wavenumber analysis is illustrated in Fig. 5e and f. Red colours stand for spectral ranges that contribute large amounts to the variability of the normalized irradiance $\chi$. White and bluish colours denote negligible and small amplitudes of the power spectral density $S_{\chi}$. We see stronger and distinctly deeper reaching variance at $3 \mathrm{~m} \mathrm{~s}^{-1}$ wind speed. In both cases irradiance fluctuations near the surface are governed by small waves of less than $5 \mathrm{~cm}$ length (the bounds of the wavelength range with most wind friction dependency $(0.007$ and $0.03 \mathrm{~m})$ are additionally marked). 
With increasing depth the capillary wave $(L<1.7 \mathrm{~cm})$ influence fades away and larger waves dominate the fluctuations, i.e. $L_{\mathrm{p}}$ and $L_{\mathrm{m}}$ grow.

Statistical characteristics of near-surface light field variability in dependence of local wind are summarized in Fig. 6 and Table 2. The maximum coefficient of variation $C V_{\max }$ is associated with the geometrical depth of the (first) focal point of capillary-gravity and small gravity waves. At a wind speed of $3 \mathrm{~m} \mathrm{~s}^{-1}, C V_{\max }=82.5 \%$ at a water depth of $1.25 \mathrm{~m} ; C V_{\max }=81.2 \%$ at $24 \mathrm{~cm}$ depth and $15 \mathrm{~m} \mathrm{~s}^{-1}$ wind. Below $80 \mathrm{~cm}$ water depth, irradiance variability decreases with growing wind. The same wind dependency shows up in the significant irradiance enhancement $\chi_{1 / 10}$ (Fig. 6b). All maximum values reach the same order of magnitude (approximately 2.8 ). At $5 \mathrm{~m}$ water depth, $\chi_{1 / 10}$ is between 1.7 and 2.4. The characteristic values $L_{\mathrm{m}}$ and $L_{\mathrm{p}}$ of the spectral analysis (Fig. 6c and d) confirm the principal trend of increasing influence of longer waves with increasing water depth. In $5 \mathrm{~m}$ depth, $L_{\mathrm{p}}=9 \mathrm{~cm}$ and $34 \mathrm{~cm}$ for wind speeds of 3 and $15 \mathrm{~m} \mathrm{~s}^{-1}$, respectively. These averaged distances between two clustered irradiance maxima are clearly visible in Fig. 4.

The wave spectra in Fig. 1 move closer together with increasing wind speed. Thus, the wave and the underwater light field characteristics approach each other. In terms of the pure geometrical influence of surface waves, differences in the statistics of the underwater irradiance fluctuations become insignificant with wind speeds of over $12 \mathrm{~m} \mathrm{~s}^{-1}$ (see Table 2). Apart from that, we have to acknowledge that the description of the sea surface using linear superposition of spectrally weighted harmonics (Gaussian surface) becomes increasingly inaccurate in higher wind speeds. Generally, wave crests are higher and sharper and the troughs are shallower and flatter. Nonlinear wave interactions, including the generation of "parasitic capillaries" on the downwind faces of gravity waves, alter the hydrodynamic properties and the shape of the free water surface (e.g. Longuet-Higgins, 1982; Zhang, 1995).

The model results may be biased because they lack windstress-dependent bubble injection into the water column. Occasional wave breaking, which generally provides the dominant source of foam at the surface and bubbles in the water, can be already observed at wind speeds about $3 \mathrm{~m} \mathrm{~s}^{-1}$. If the wind speed exceeds $7 \mathrm{~m} \mathrm{~s}^{-1}$, horizontally uniform bubble layers can evolve in the first metres and persist over hours (Thorpe, 1992). At the wind speeds under consideration (3$15 \mathrm{~m} \mathrm{~s}^{-1}$ ), the contribution of foam to the (broadband) surface albedo, and thus irradiance transmission, is very limited despite its high reflectance (Zhang et al., 2006). More relevant are air bubbles in the upper water layer as they cause enhanced reflectance (in clear water the reflectance has a strong dependence on the light spectrum). But in contrast to the upwelling light, bubbles induce only very small enhancement in downwelling irradiance within the top several tens of centimetres just beneath the surface and below that layer, $E_{\mathrm{d}}$ is reduced compared to bubble-free water (Stramski and Tegowski, 2001). For this reason we must consider that air bubbles in water impair the effectiveness of wave lensing, and thus damp the intensity of the described fluctuations, in particular at increasing wind speed. Nevertheless, for the sake of model simplicity and a better inter-comparison of the model results, whitecaps and bubbles are neglected within all presented radiative transfer simulations.

\subsubsection{The influence of growing waves}

It is obvious that no underwater light fluctuations can evolve from a perfectly flat water surface, i.e. at $0 \mathrm{~m} \mathrm{~s}^{-1}$ wind speed we have the absolute fluctuation minimum in terms of $C V$, et cetera. A threshold wind speed or friction velocity is required to actually produce waves. The reason is clearly that energy input from the wind does not exceed viscous dissipation below this threshold (Donelan and Plant, 2009). The further growth of small-scale waves depends on the energy input by the turbulent wind field (i.e. the wave field develops with increasing fetch or duration) on the energy transfer between waves of different length by nonlinear wave-wave interaction, and on the energy dissipation by wave breaking, viscous dissipation, and turbulent diffusion (Phillips, 1985). The simulation results that are shown in the previous Sect. 3.1 consider the short-wave part from Eq. (1) only (Fig. 1, solid lines). Over the open ocean, we must consider all the just mentioned aspects of wave field interactions and assume a long-wave modification of the spectra (dashed lines in Fig. 1). This in particular concerns the wave fields at low and moderate wind conditions, where ultra-gravity waves (wavelength range approximately $1.7 \mathrm{~cm}$ to $1.6 \mathrm{~m}$ ) are more pronounced and higher.

Figure 7 shows the corresponding influence on the underwater light field in terms of the significant irradiance enhancement. In the case of strong wind, the fluctuation statistics remain unchanged, because the wave spectra have almost the same shape. Whereas at low wind speed of $3 \mathrm{~m} \mathrm{~s}^{-1}$, we observe clearly intensified irradiance peaks due to the lensing effect of steeper ultra-gravity waves. Within the depth range of 0.5 to $3 \mathrm{~m}$, maximum light flashes exceed $10 \overline{E_{\mathrm{d}}}$ $\left(\chi_{\max }=11.2\right)$, the skewness of the $E_{\mathrm{d}}$ probability distribution is above 2 (instead of 1.5 in the reference case), the excess kurtosis exhibits values of 7 (instead of 3), and $C V$ is around $100 \%$. Consequently, the spectral characteristics of light fluctuations change too; $L_{\mathrm{m}}$ and $L_{\mathrm{p}}$ grow faster with increasing depth, e.g. $L_{\mathrm{p}}\left(z_{t}=5 \mathrm{~m}\right)=28 \mathrm{~cm}$ (instead of $9 \mathrm{~cm}$ ). The principal wind-dependency of light field statistics (Fig. 6) is retained, but with amplified values at low and moderate wind speeds (Table 2). 

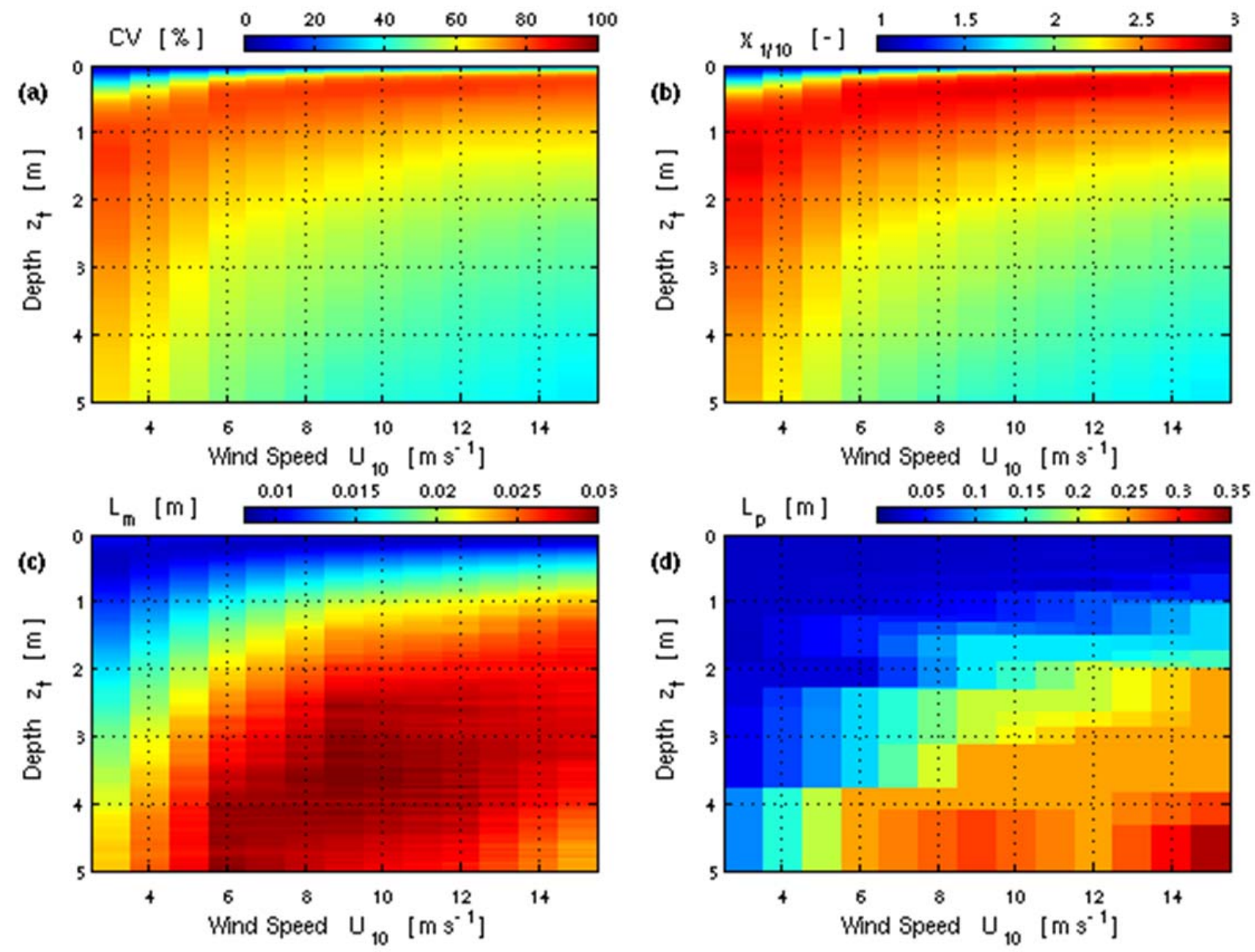

Fig. 6. The influence of local wind on the underwater light field near the water surface; (a) coefficient of variation $C V$ of $E_{\mathrm{d}}$ fluctuations; (b) significant irradiance enhancement $\chi_{1 / 10}$; (c) mean fluctuation length $L_{\mathrm{m}}$; (d) spectral peak length $L_{\mathrm{p}}$.

Table 2. Numerical quantity values of maximum light fluctuations for different wind regimes; the numbers in brackets denote the influence of growing waves.

\begin{tabular}{|c|c|c|c|c|c|c|c|}
\hline Wind speed & $U_{10}$ & {$\left[\mathrm{~m} \mathrm{~s}^{-1}\right]$} & 3 & 6 & 9 & 12 & 15 \\
\hline $\begin{array}{l}\text { Depth of strongest } \\
\text { fluctuations }\end{array}$ & $z_{t}\left(\chi_{1 / 10 \max }\right)$ & {$[\mathrm{m}]$} & $1.25(1.75)$ & $0.52(0.69)$ & $0.40(0.40)$ & $0.32(0.28)$ & $0.24(0.21)$ \\
\hline $\begin{array}{l}\text { Maximum significant } \\
\text { irradiance enhancement }\end{array}$ & $\chi_{1 / 10 \max }$ & {$[-]$} & $2.8(3.4)$ & $2.8(2.9)$ & $2.8(2.8)$ & $2.8(2.8)$ & $2.8(2.8)$ \\
\hline $\begin{array}{l}\text { Maximum irradiance } \\
\text { enhancement }\end{array}$ & $\chi_{\max }$ & {$[-]$} & $7.6(11.2)$ & $7.7(8.5)$ & $7.5(8.6)$ & $7.6(7.3)$ & $7.0(7.4)$ \\
\hline $\begin{array}{l}\text { Maximum coefficient } \\
\text { of variation }\end{array}$ & $C V_{\max }$ & {$[\%]$} & $82.5(103.1)$ & $80.9(83.5)$ & $82.1(82.8)$ & $82.5(82.8)$ & $81.2(81.9)$ \\
\hline Maximum skewness & $\gamma_{1 \max }$ & {$[-]$} & $1.6(2.2)$ & $1.5(1.6)$ & $1.5(1.5)$ & $1.5(1.5)$ & $1.5(1.5)$ \\
\hline $\begin{array}{l}\text { Maximum excess } \\
\text { kurtosis }\end{array}$ & $\gamma_{2 \max }$ & {$[-]$} & $2.8(7.2)$ & $2.6(4.0)$ & $2.8(4.0)$ & $2.7(3.2)$ & $3.0(3.0)$ \\
\hline
\end{tabular}




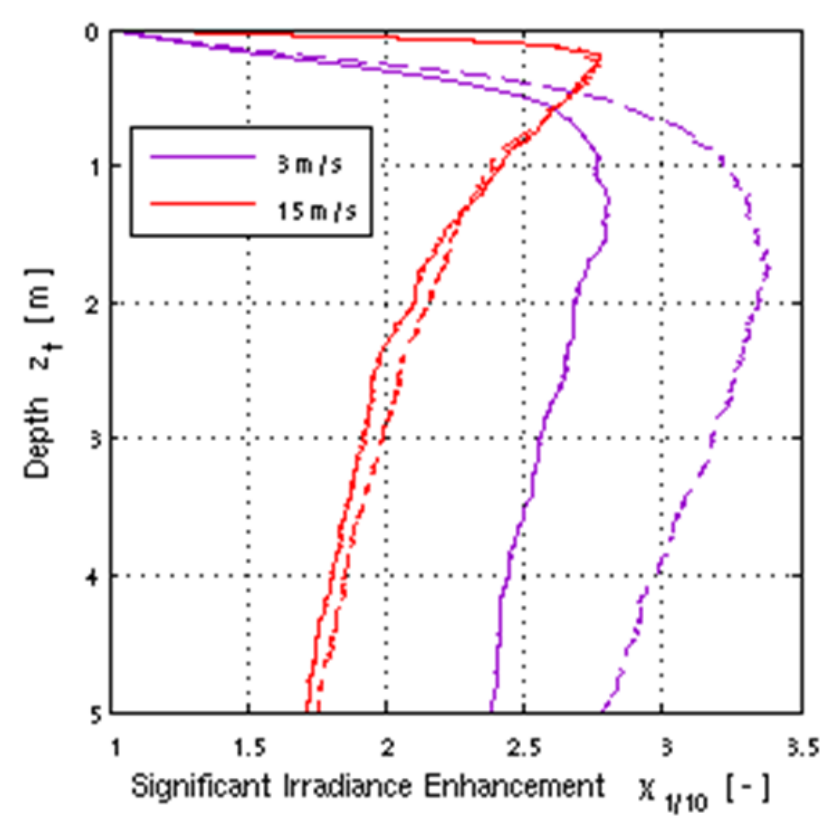

Fig. 7. Significant irradiance enhancement $\chi_{1 / 10}$ for two wind velocities with (dashed) and without (solid lines) long-wave modification of the applied wave spectra (Fig. 1).

\subsection{Influence of the sea state on the underwater light field}

Now we focus on light field changes due to variations of the long-wave part of the sea spectrum which is referred to as sea state. The directly wind-dependent short-wave part is also included in the applied spectra. The evaluable model domain covers $500 \mathrm{~m}$ horizontally and up to $100 \mathrm{~m}$ vertically (water depth); the model resolution is $10 \mathrm{~cm}$ in both directions. The model takes into account all fractions of direct and scattered radiation.

We would like to point out that the use of the two irradiance "detector sizes" of $2.5 \mathrm{~mm}$ for the near-surface model and $10 \mathrm{~cm}$ for the deep-water model may lead to differing results in the statistical analysis. The rather coarse resolution in the deep-water model makes sense to cover the large study area (of $50000 \mathrm{~m}^{2}$ ), and it takes into consideration the fact that the saturation time of radiometers typically increases with increasing water depth. The broader detector averages out substantial parts of the high-frequency fluctuations and diminishes the amplitudes of light flashes near the surface. If we carefully look at Fig. 4 and visually average the spatial $E_{\mathrm{d}}$ distribution over $10 \mathrm{~cm}$ horizontally, we will find actually higher variability at $5 \mathrm{~m}$ depth in the case of strong wind which contradicts the statements in Fig. 6a. Darecki et al. (2011) compare the effects of different collector diameters (ranging from 2.5 to $23 \mathrm{~mm}$ ) on temporal $E_{\mathrm{d}}$ measurements; their data from $2.7 \mathrm{~m}$ depth do not reveal a clear effect of the collector size on the $E_{\mathrm{d}}(t)$ signal (different IOPs and ir- radiation conditions as in our case). On the one hand this is due to the scattering processes in water and the associated increasing diffuseness of light, and on the other hand it shows the vanishing influence of the high-frequency contribution to the light field variance which depends on the water surface geometry (as shown in Fig. 6c and d). Below approximately $10 \mathrm{~m}$ water depth, the used model resolution of $d x=10 \mathrm{~cm}$ is perfectly sufficient to characterize the light field fluctuations.

Figure 8 shows the computed irradiance distribution beneath the most prevalent sea state with $H_{\mathrm{s}}=2 \mathrm{~m}, T_{\mathrm{p}}$ $=8 \mathrm{~s}$ (both input parameters for the spectrum Eq. 4), and $U_{10}=4.8 \mathrm{~m} \mathrm{~s}^{-1}$. The 10 and $5 \% E_{\mathrm{d}}$ contour lines are each highlighted to illustrate the depth-effect of the irregularly deflected sea surface. In the example, the wave-induced mixed layer depth, where under certain circumstances enhanced biomass concentration (a deep chlorophyll $a$ maximum) can be expected, is approximately at $35.5 \mathrm{~m}$ (Eq. 3). Here, the averaged downwelling irradiance is $27.7 \%$ (of the surface value), individual $E_{\mathrm{d}}$ values vary between 22.4 and $39.2 \%$ $\left(\chi_{\max }=1.44, C V=8.15 \%\right)$, and the mean fluctuation length $L_{\mathrm{m}}$ is $1.33 \mathrm{~m}$ which gives a mean fluctuation period of approximately $1 \mathrm{~s}$ (Eq. 2). According to the model, light flashes $(\chi=1.5)$ can appear down to $30 \mathrm{~m}$ water depth. Waveinduced light variability can be observed even at the lower boundary of the model domain, i.e. at $90 \mathrm{~m}$ depth $\overline{E_{\mathrm{d}}}=3.2 \%$ (the $E_{\mathrm{d}}$ minimum and maximum is at 2.9 and $3.4 \%$, respectively), $C V=2.84 \%$, and the mean (peak) fluctuation period is around $6 \mathrm{~s}$.

The statistical characteristics of the simulated irradiance variability with respect to different sea states are summarized in Fig. 9. The data refer to four water depths with $\overline{E_{\mathrm{d}}}=50,25$, 10 , and $5 \%$ of the surface irradiance value, which approximately correspond to 20, 40, 60, and $80 \mathrm{~m}$, respectively. Figure 10 provides additional information on vertical changes of selected fluctuation parameters, where both the sea state related minimum and maximum values are identified. The red lines in Fig. 10a-c mark the parameter values that are averaged over the range of highest occurrence probability shown by the white frame in Fig. 2.

With regards to the $C V$ (Figs. 9a-d and 10a), the strongest light fluctuations appear at particular steep sea states with high $H / L$ values but low probability of occurrence (see Fig. 2). Indirectly, the statement is also true for high wind speeds, since wind speed and sea state are correlated. It is obvious that fully developed seas shape larger lens surfaces with an enhanced depth effect. Fig. 9d shows the $C V$ at $80 \mathrm{~m}$ water depth, ranging from $1.1 \%\left(H_{\mathrm{s}}=0.5 \mathrm{~m}, T=9 \mathrm{~s}, H / L\right.$ $=0.004)$ to $14.3 \%\left(H_{\mathrm{s}}=3.5 \mathrm{~m}, T=5 \mathrm{~s}, H / L=0.09\right)$, but a $C V$ around $4.7 \%$ being most likely. A special feature noticeable at the $50 \% E_{\mathrm{d}}$ level with $H_{\mathrm{s}}=0.5 \mathrm{~m}$ (Fig. 9a) is the slight increase of fluctuations in the case of a wave period of $11 \mathrm{~s}$ compared to the case with $5 \mathrm{~s}$, where $C V$ is 16.7 and $13.4 \%$, respectively. The wave steepness is smaller, thus the enhanced $C V$ must be due to the slightly enhanced local wind speed $U_{10}$ that is characteristic for the $11 \mathrm{~s}$ sea state (see 


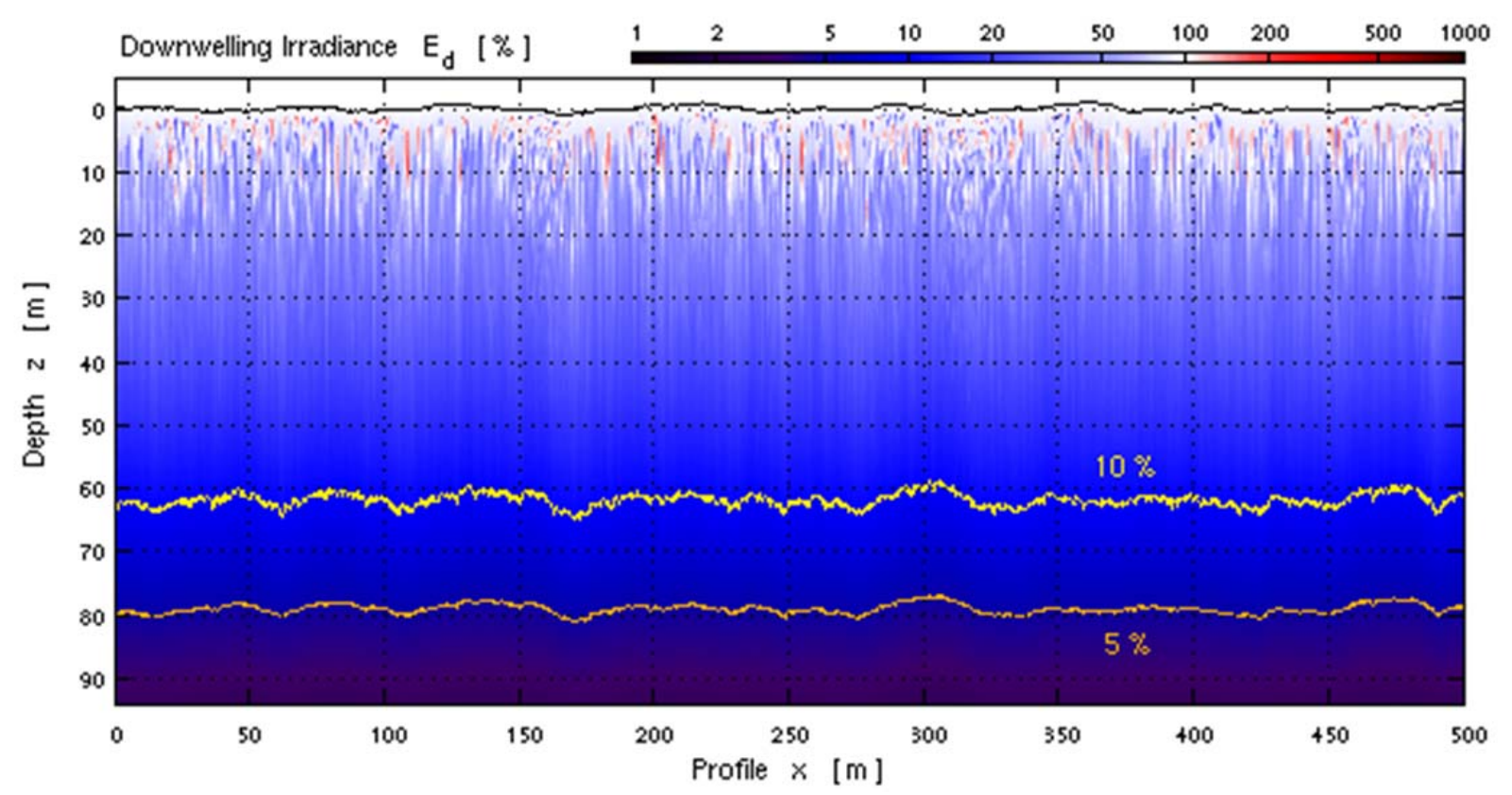

Fig. 8. Spatial distribution of downwelling irradiance $E_{\mathrm{d}}$ for the sea state of highest occurrence probability with a resolution of $d x=10 \mathrm{~cm}$, the 10 and $5 \%$ irradiance levels are additionally marked.

Fig. 2). This observation is an indication of the still present depth effectiveness of a local wind (and thus of capillarygravity waves) at $20 \mathrm{~m}$ depth.

With regards to $\chi_{1 / 10}$ and $\chi_{\max }$ (Figs. $9 \mathrm{e}-1$ and 10b), we see the same depth changes as in $C V$. As mentioned before, $\chi_{1 / 10}$ is a good benchmark of the maximum measurable irradiance enhancement (with e.g. a RAMSES-ACC-VIS). At $20 \mathrm{~m}$ water depth, our comparative measurements mostly showed $E_{\mathrm{d}}$ maxima being in the order of $1.3-1.4 \overline{E_{\mathrm{d}}}$ which absolutely fits to the simulated $\chi_{1 / 10}$ of the corresponding sea states (Fig. 9e). In rare events, irradiance values of more than $1.5 \overline{E_{\mathrm{d}}}$ were measured at this depth level under moderate sea conditions (Veal et al., 2010; Hieronymi et al., 2012). According to Figs. 9i and 10b, the mean value of the simulated irradiance peaks $\chi_{\max }$ within the range of high occurrence probability is around 2, i.e. still at $20 \mathrm{~m}$ depth, $E_{\mathrm{d}}$ can achieve maximum values of $100 \%$ of the surface irradiation. Theoretically, $\chi_{\max }$ can be up to 2.5 (at $H_{\mathrm{s}}=2.5 \mathrm{~m}, T=4 \mathrm{~s}$, $H / L=0.1$ ). In case of perfect single waves, $\chi_{\max }$ can be 10 at $20 \mathrm{~m}$ and 1.5 at $80 \mathrm{~m}$ depth, respectively (Hieronymi, 2011). In reality, the surface roughness causes considerable noise in the light regime that dampens the lensing effectiveness of longer waves. However, deep-reaching light flashes originate from the superposition with fully developed gravity waves. They can reach $30 \mathrm{~m}$ depth under moderate and prevailing sea conditions but down to $75 \mathrm{~m}$ in extreme cases (Fig. 10b).

The wavenumber analysis of underwater irradiance fluctuations confirms the increasing importance of growing surface waves (Figs. 9m-t and 10c). $L_{\mathrm{m}}$ provides a clearer picture of the recurrence of radiative peaks as a function of different sea states compared to the rather noisy $L_{\mathrm{p}}$. But $L_{\mathrm{p}}$ gives a direct hint on the mean distance between two intense irradiance peaks, and thus about the magnitude of surface wavelengths that dominate the irradiance variability. As seen in Fig. 9r, the light variability of flatter sea states is (even at $40 \mathrm{~m}$ depth) still dominated by ultra-gravity waves, i.e. it is associated with local wind. The differences in $L_{\mathrm{m}}$ increase with water depth. At $80 \mathrm{~m}$ depth, $L_{\mathrm{m}}$ is between 5 and $45 \mathrm{~m}$, the mean value is around $30 \mathrm{~m}$. The dependency of the mean fluctuation length on the wave steepness becomes clear, if we recall the focusing effect of single waves again (Hieronymi et al., 2012). The steeper a wave, the closer is its focal point to the sea surface, i.e. if we look at a certain depth level, then the focal point of a steeper wave must be associated with a longer wavelength. This mechanism is mirrored for example in Fig. 9p, where steeper sea states are associated with larger distances between relatively strong irradiance enhancements.

Figure 11 points out the influence of surface waves on the irradiance fluctuations at certain depths, or more precisely it marks the wavelengths that contribute at least $0.1 \%$ to the total spectral variance of the signal. Both used model resolutions and all investigated cases are considered in this figure. The lower boundary of the spectral wavelength range is partly dashed which indicates that shorter wavelengths occur, but due to resolution limitations no statements can be made about this range. Local wind primarily affects the light fluctuations down to roughly $10 \mathrm{~m}$ depth, if we consider the 

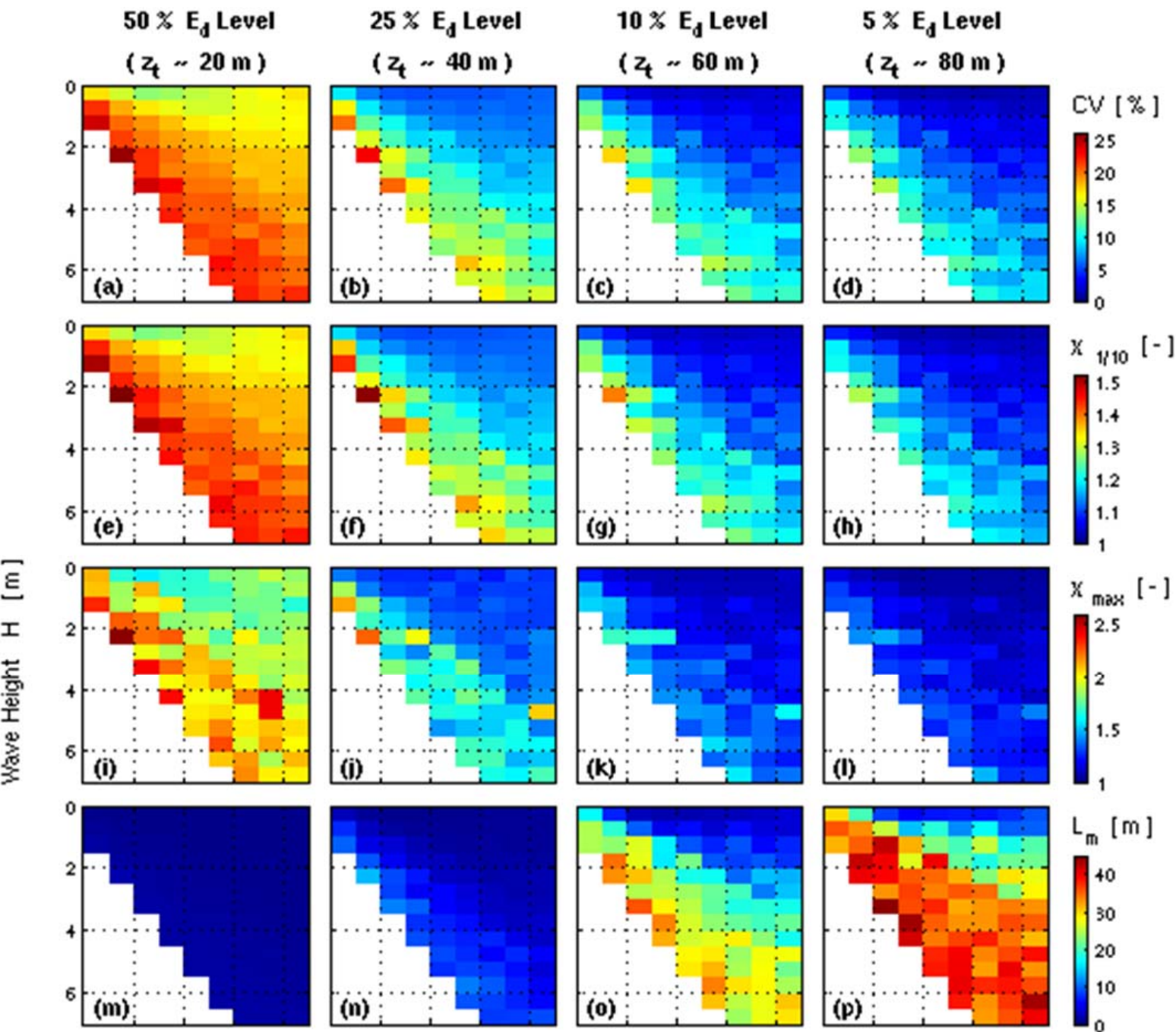

$L_{m}[\mathrm{~m}]$
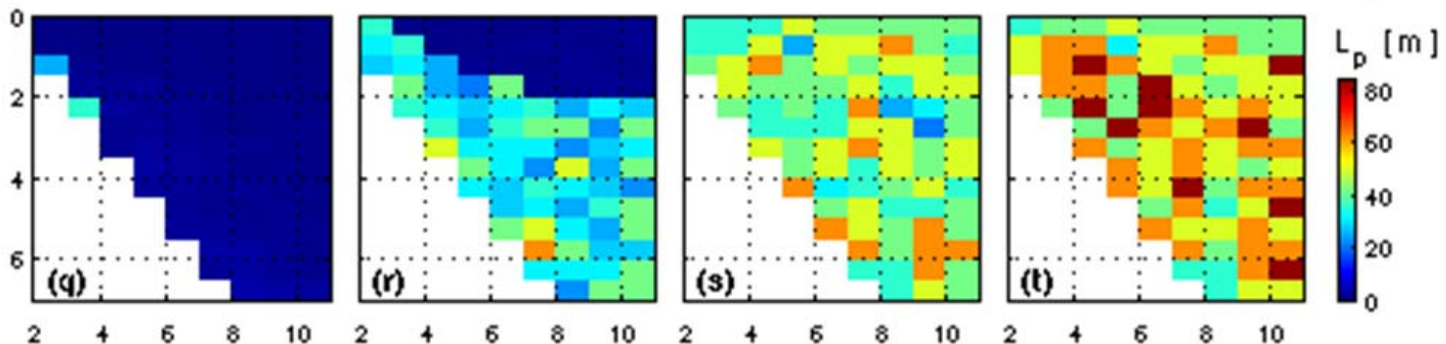

Wave Period T [s]

Fig. 9. Statistical characteristics of the influence of the sea states (Fig. 2) on the underwater irradiance variability at the 50, 25, 10, and $5 \%$ $E_{\mathrm{d}}$ depth level $\left(z_{t}=19.7,38.5,62.0\right.$, and $79.2 \mathrm{~m}$ respectively) based on the model with $d x=10 \mathrm{~cm}$ resolution; (a)-(d): coefficient of variation $C V$; (e)-(h): significant irradiance enhancement $\chi_{1 / 10}$; (i)-(l): maximum normalized irradiance $\chi_{\max } ;$ (m)-(p): mean fluctuation length $L_{\mathrm{m}}$; (q)-(t): spectral peak length $L_{\mathrm{p}}$.

most wind-dependent capillary and capillary-gravity waves of 0.7 to $3 \mathrm{~cm}$ length only. The depth-impact of ultra-gravity waves (up to $1 \mathrm{~s}$ wave period or $1.5 \mathrm{~m}$ length), which are also closely related to the prevailing wind regime, is restricted to approximately $50 \mathrm{~m}$ depth. Waves at the surface must be at least $4 \mathrm{~m}$ long to be able to affect the irradiance variability at a water depth of $80 \mathrm{~m}$. On the other hand, waves longer than $20 \mathrm{~cm}$ do not contribute considerably to the irradiance 

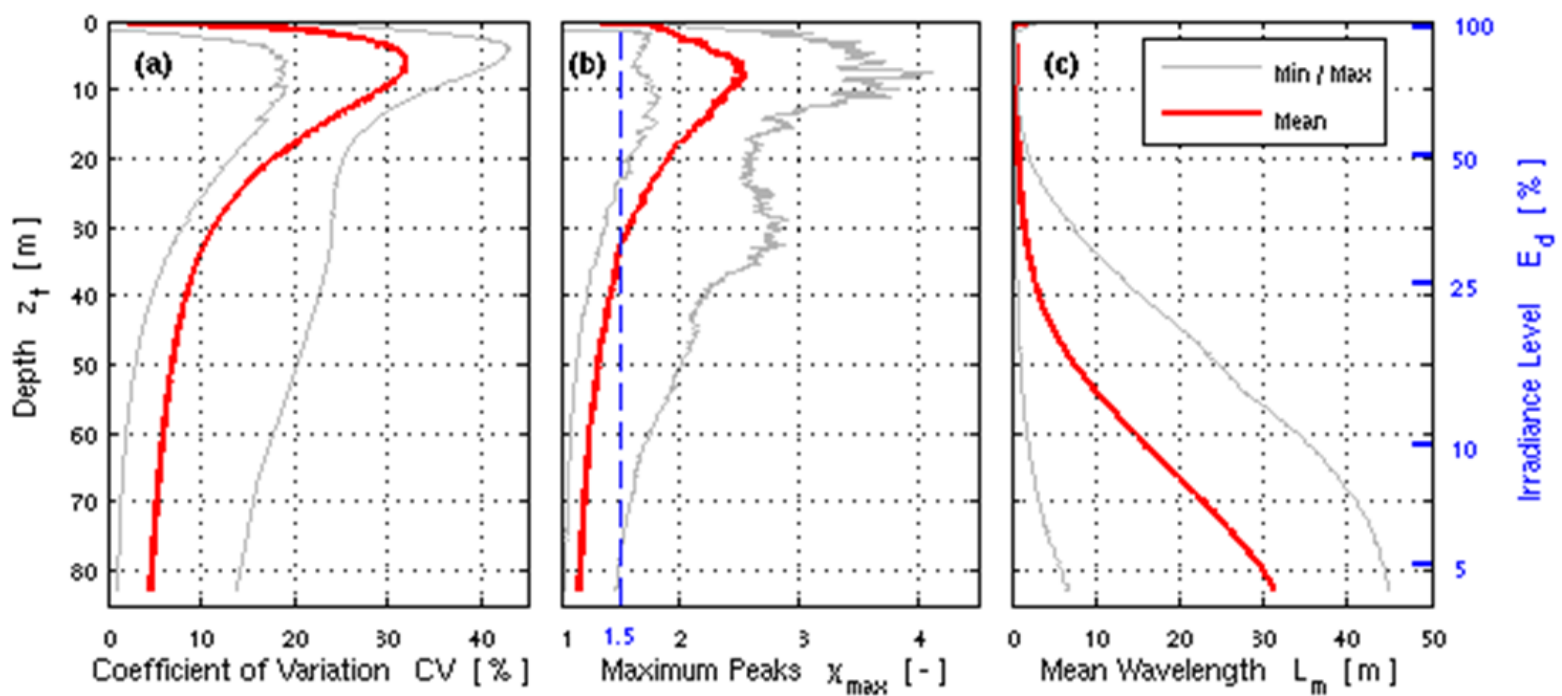

Fig. 10. Summary of light field statistics of all sea states under consideration with the $d x=10 \mathrm{~cm}$ model; the grey lines show the respective minimum and maximum values, the red lines present the average of the values due to the sea states with highest occurrence probability (in the white framed in Fig. 2); (a): coefficient of variation $C V$; (b): maximum normalized downwelling irradiance $\chi_{\max }$; (c): mean fluctuation length $L_{\mathrm{m}}$.

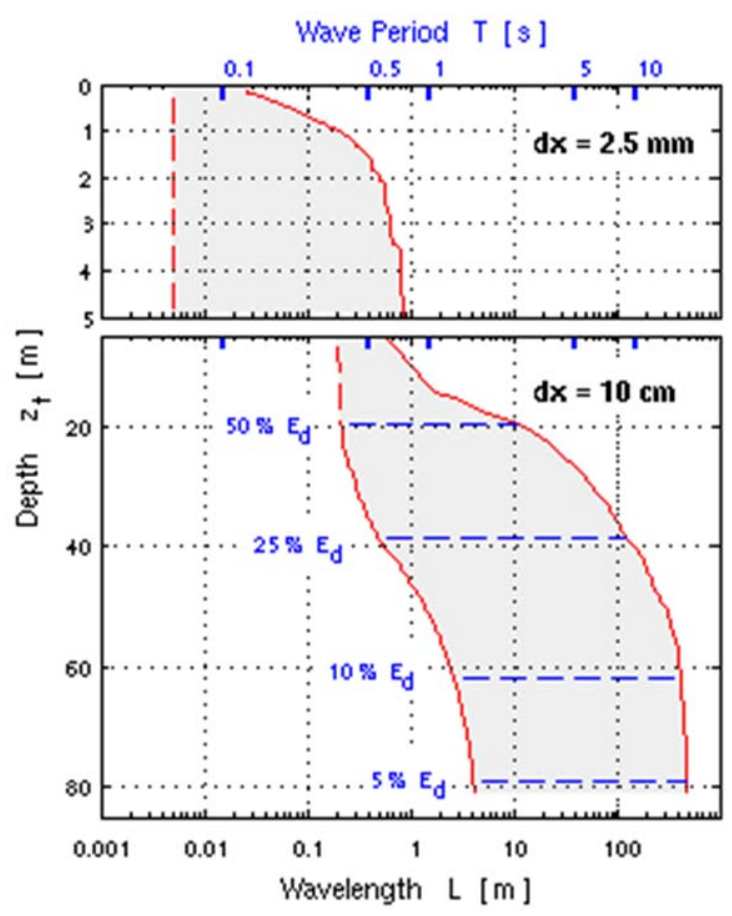

Fig. 11. Range of waves that influence the light field at depth; the red lines represent the minimum and maximum wavelengths that contribute at least $0.1 \%$ (one per-mille) to the first spectral moment $m_{1}$ of $S_{\chi}$ (integral of the wavenumber-weighted variance spectrum of $\chi$ fluctuations, Eq. 7); top: near-surface model with $d x=2.5 \mathrm{~mm}$; below: $d x=10 \mathrm{~cm}$ model resolution. variability at $1 \mathrm{~m}$ depth. The light field influence due to ordinary gravity waves ( $>1 \mathrm{~s}$ period) starts at $13 \mathrm{~m}$ water depth. And even swell waves potentially influence the light field at greater depths, e.g. a $10 \mathrm{~s}$ swell-dominated sea state affects the light field below $40 \mathrm{~m}$ depth.

\subsection{Discussion}

We now want to put the simulation results into context with previous publications and measurements. Remember that our model assumes optimal conditions for wave-induced underwater light fluctuations, for example, an extreme clear atmosphere that causes $10 \%$ diffuse surface irradiation only and the high standing sun $\left(\theta_{\mathrm{s}}=0^{\circ}\right)$.

\subsubsection{Discussion of the applied methods}

Our Monte Carlo model is based on a completely novel approach (Hieronymi, 2011). It is optimized for investigations of the light field below arbitrary sea surfaces. The model yields reliable results on the spatial $E_{\mathrm{d}}$ distribution, from which all statistical properties of the light field including the periodicity of extreme values can be deduced. In comparison to other models (e.g. Deckert and Michael, 2006; D'Alimonte et al., 2010; You et al., 2010; Shen et al., 2011), our model provides a high information density with high spatial resolution down to much greater depths $(100 \mathrm{~m})$. And yet our model is relatively fast (light fields below more than 100 different wave profiles were investigated for this study).

The description of the sea surface and its implementation into the radiative transfer model remains a critical factor 
that still leaves room for improvements. Wave spectra, as the Pierson-Moskowitz (PM) spectrum, have been utilized with this regard (e.g. by Nikolayev et al., 1972; Weber, 2010; You et al., 2010). However, the $P M$ spectrum applies to gravity waves in a fully developed sea, which means that the wave growth has reached a point of equilibrium with the wind input. The $P M$ spectrum does actually not apply to capillary and ultra-gravity waves that are most important in terms of light field variability (at least near the surface); the validity of such a long-wave spectrum is limited to wavenumbers up to approximately 10 times its spectral peak $k_{\mathrm{p}}$ (e.g. Leykin and Rozenberg, 1984; Elfouhaily et al., 2009). Over the open ocean, sea states are very often influenced or even dominated by swells (e.g. as seen in Fig. 2, wave classes with large periods appear despite the fact that there is not enough prevailing wind to actually generate these long waves). In the presence of swells, the wave spectrum exhibits a narrow peak, or in combination with a wind sea it shows a bimodal shape (e.g. ITTC, 2002); both spectral shapes differ from the PM shape. Nevertheless, the spectra that we use include all relevant classes of waves ranging from capillary to swell waves; the long-wave part is always described by the Pierson-Moskowitz spectrum (Eq. 4) and the wind-specific short-wave part is additionally accounted for.

In some radiative transfer models (e.g. HydroLight), the wind-dependent roughness of the sea surface is implemented by the statistical slope distribution of water facets according to Cox and Munk (1954). Our wave profiles, which are generated from the unified spectra for long and short waves, have a slope distribution that can differ from the Cox-Munk distribution. There is a good match at moderate wind speeds around $5 \mathrm{~m} \mathrm{~s}^{-1}$, but at less wind we observe a narrower distribution and at higher wind speeds we have more frequently steeper slopes compared to Cox-Munk. One explanation for the deviations is that we partly consider extreme sea events with significant wave heights up to $7 \mathrm{~m}$. However, there are clear differences at high wind speeds $\left(>10 \mathrm{~m} \mathrm{~s}^{-1}\right)$ that raise the question on the validity of our approach with linear wave theory and the disregard of nonlinearities. Just recently, there have been two studies on polarized underwater light fields by You et al. (2011) and Xu et al. (2011), where three-dimensional wave elevations were derived from highresolution wave slope measurements and from a numerical "high-order spectral method", respectively. Both realizations of the sea surface sound promising and could be applied in future studies. With this regard, we would expect that the light field variance rather weakens at strong wind and increases at light wind in comparison with our model.

Our model considers the exact shape of wave profiles in the $x$ and $z$ directions (with $d x=0.1 \mathrm{~mm}$ ). Viewed statistically, the sea states investigated can have maximum wave amplitudes of more than $5 \mathrm{~m}$ around the mean waterline (e.g. with $H_{\mathrm{s}}=7 \mathrm{~m}$ ). As far as we know, there is only one comparable model by D'Alimonte et al. (2010) that includes vertical wave elevations as well. Regarding the precise wave geometry gives a more realistic picture of the underwater irradiance distribution, i.e. otherwise, in case of a $z$-invariant light input, the lensing pattern would be distorted. However, the differences in the light field statistics are generally minor.

\subsubsection{Discussion of the simulation results}

With regards to the magnitude of irradiance enhancements, temporally high resolution measurements of the downwelling irradiance show that near the surface instantaneous light pulses can exceed $10 \overline{E_{\mathrm{d}}}$; the amplitude of the strongest flash was in excess of $15 \overline{E_{\mathrm{d}}}$ (measured with a $2.5 \mathrm{~mm}$ collector at $0.86 \mathrm{~m}$ water depth) (Darecki et al., 2011; Gernez et al., 2011). Our near-surface model is capable of reproducing such irradiance enhancements for light to moderate wind conditions and under the presence of steeper ultra-gravity waves. In theory, irradiance pulses can exceed the mean irradiance by a factor of 40 at a water depth of $1 \mathrm{~m}$ under the assumption of an ideal steep wave of $80 \mathrm{~cm}$ length (Hieronymi et al., 2012).

According to our model, light flashes can occur much deeper than observed so far. Under realistic conditions, in terms of the sea state, irradiance peaks with $1.5 \overline{E_{\mathrm{d}}}$ should be still possible at $30 \mathrm{~m}$ water depth (Fig. 10b), but their occurrence frequency is low. Up to now, light flashes were recorded down to a depth of $21 \mathrm{~m}$ only (Veal et al., 2010; Hieronymi et al., 2012). Irradiance variability ( $C V)$ of around $10 \%$ has been detected at the depth range of 30 to $35 \mathrm{~m}$ (Stramska and Dickey, 1998; Veal et al., 2010) which absolutely fits to our simulation results for moderate sea states (Fig. 10a). However, the simulated deep-water maximum values that are presented in this article should be verified with more precisely and temporally high resolution insitu measurements.

Some publications have compiled statistics on the relationship between wind conditions and underwater light field fluctuations (e.g. Nikolayev et al., 1972; Dera and Stramski, 1986; Gernez and Antoine, 2009; Weber, 2010; Hieronymi and Macke, 2010; Darecki et al., 2011). There is general agreement that the most favorable conditions for light focusing by waves prevail at moderate winds between 2 and $7 \mathrm{~m} \mathrm{~s}^{-1}$. Wind-related capillary waves at the surface essentially blur the spatial structure of the light field and decrease the lensing efficiency of small ultra-gravity waves which, at a standard depth of $1 \mathrm{~m}$, cause the most intense fluctuations (Hieronymi, 2011). Our model, which refers to a wind wave description that requires a minimum wind speed of $3 \mathrm{~m} \mathrm{~s}^{-1}$, provides the geometrical explanation and shows the interactions of different wave types. Related to the depth range of 1 to $5 \mathrm{~m}$, our simulation results confirm the known winddependency (Fig. 6a). But the model also shows that higher wind speeds induce stronger fluctuations within the first half metre which is also shown by Weber (2010); this is due to steeper capillary-gravity waves that develop focal points closer to the sea surface. 
Nikolayev et al. (1972) have analyzed the relationship between wind-dependent wave spectra and corresponding energy density spectra of illumination fluctuations at several water depths; they showed the shift of the fluctuation peak towards lower frequencies with increasing depth, and that higher wind speeds have stronger low-frequency peaks and a sharp drop in the spectral density towards higher frequency. These observations are in good agreement with the wavenumber analysis of our modelled light fields (Figs. 5e-f and $6 \mathrm{c}-\mathrm{d})$.

The sea state dependency of irradiance variability is less well-documented (most relevant studies concentrate on the near-surface region). By means of our model, we have demonstrated that more developed gravity waves - here one can speak of a sea state - primarily affect deeper water layers, but essentially not the upper most $10 \mathrm{~m}$. This statement is confirmed by Gernez and Antoine (2009), who showed that gravity waves have no evident impact on irradiance fluctuations at approximately $4 \mathrm{~m}$ depth and that the wave height has relatively little influence on $C V$ and the spectral peak period of fluctuations. Our earlier measuring campaigns suggested that below $5 \mathrm{~m}$ depth, light fluctuations can be described more accurately in terms of wave height and period, rather than wind speed, and that between 3 and $25 \mathrm{~m}$ water depth waves with $H_{\mathrm{s}}$ of 1.5 to $2.5 \mathrm{~m}$ provoke the strongest intensity fluctuations (Hieronymi and Macke, 2010). In this sense a quite similar conclusion can be drawn from data of Nikolayev and Yakubenko (1978). With regard to a water depth of $20 \mathrm{~m}$, seas with small wave heights $(<0.4 \mathrm{~m})$ cause considerably less light fluctuation compared to higher waves (of e.g. $1.5 \mathrm{~m}$ height). The simulation results of this study are in line with these observations if we consider the most likely sea states during the measuring campaigns (see Fig. 9a). But the findings also suggest that it is rather the wave steepness $H / L$ of the characteristic wave of a sea state that influences the light variability at greater depths, namely the steeper a wave system, the stronger are the underwater light field fluctuations. This is exactly the same relation for single waves (Hieronymi et al., 2012) and of course it applies for each constant wavelength $L$.

Steep wave systems are mostly associated with strong wind (Fig. 2). In this case it has to be assumed that in reality the lensing efficiency is considerably reduced because of nonlinear hydrodynamic interactions at the surface and air bubbles that are induced by breaking waves (e.g. Stramski and Tegowski, 2001). Thus, it has to be assumed that at high wind speed our model overestimates the strength of irradiance variability down the water column. However, the model assumption of vertical solar insolation $\left(\theta_{\mathrm{S}}=0^{\circ}\right)$ can only occur within the tropics where the yearly mean of the wind speed does not exceed $9 \mathrm{~m} \mathrm{~s}^{-1}$ (Sterl and Caires, 2005). Our model generally shows very good agreement with observations under such light to moderate wind conditions.

Another question is whether different sea states at constant wind speed actually have an impact on the mean down- welling irradiance in the water column. We have slightly different slope distributions due to the differing long-wave part of the spectrum, i.e. the presence of a more developed sea is comparable with slightly higher wind speeds (related to the Cox-Munk distribution). Within our simulations we have no considerable changes of $\overline{E_{\mathrm{d}}}$ due to wind or the sea state. This is mainly because of the perpendicular light input where the irradiance reflectance is very low and almost wind-independent (Preisendorfer and Mobley, 1986). But we would conclude that there is an effect at low sun positions, because then more light is reflected at the stronger roughened surface.

The model results that are shown in this work express the upper range and maximum of downwelling irradiance variability in the upper ocean; the simulations have been carried out for optimal conditions for light-focusing. It is clear that lower sun positions, a higher proportion of diffuse sky illumination, or less clear sea water reduce the intensity of light fluctuations and lead to a faster decay of the variability with increasing depth (e.g. Stramski, 1986; Gernez and Antoine, 2009; Hieronymi, 2011). Also other factors such as the refractive ratio of the air-sea interface (e.g. influenced by the water temperature, salinity, as well as foam and biofilms at the sea surface) and the absorption and scattering properties of water ingredients (as air bubbles, hydrosols, coloured dissolved organic matter, and plankton) affect the appearance of the underwater light field and may change its fluctuation statistics. The quantitative influence of such aspects on irradiance fluctuations should be addressed in future scientific works. Another important research area will be to characterize the relationship between the wavy sea surface and the upward directed radiation in order to draw conclusions on the variability of the upwelling irradiance, the water-leaving radiance, and the remote sensing reflectance.

The variability of the light availability in water can have impacts on several biogeochemical processes. Quequiner and Legendre (1986) for example showed that differently fast fluctuating light affects phytoplankton in terms of their growth, photosynthetic characteristics, and their adaptation to the illumination regime. Our work gives hints on the manner in which irradiance is delivered at various water depths. This valuation could be used for investigations of different light-dependent processes in the ocean.

\section{Summary}

This paper presents the first systematic analysis of the influence of various wind and wave regimes on the downwelling irradiance variability within the upper ocean mixed layer down to $100 \mathrm{~m}$ depth. The study is based on a twodimensional Monte Carlo radiative transfer model the principle suitability of which is proven by comparisons with several corresponding in-situ measurements and with the radiative transfer model HydroLight (Hieronymi et al., 2012). We 
assume model conditions that favor the development of extreme light fluctuations within the entire lit water column, i.e. monochromatic light at $490 \mathrm{~nm}$, high standing sun $\left(0^{\circ}\right)$, a very low portion of diffuse sky radiation $(10 \%)$, and very clear well-mixed sea water with a low chlorophyll $a$ content of $0.1 \mathrm{mg} \mathrm{m}^{-3}$. Any arbitrary wave profile can be implemented into the model in order to simulate the resulting underwater light field. Two model resolutions are chosen, the near-surface model is resolved with $2.5 \mathrm{~mm}$ horizontally and the deep-water model with $10 \mathrm{~cm}$ respectively. The basic difference is that the latter considers all direct and diffuse radiation in the water, while the near-surface model considers the direct light beam only.

In a first step, we look at the influence of wind on the light field near the surface. As a locally occurring event, wind primarily affects the steepness of small waves in the transition region from capillary to ultra-gravity waves. The near-surface light field is dominated by the focusing effect of these small waves. In case of high wind speeds, we have steep capillary-gravity waves that build up focal points closer to the surface than flatter waves that develop at low wind speeds. For this reason we have a vertical shift of the maximum light fluctuations towards the surface at growing wind. However, maximum irradiance peaks can be observed at relatively low wind speeds of 3 to $5 \mathrm{~m} \mathrm{~s}^{-1}$ (where $3 \mathrm{~m} \mathrm{~s}^{-1}$ is the lowest wind speed under consideration); within the depth range of 0.5 to $3 \mathrm{~m}$, maximum light flashes can exceed $7 \overline{E_{\mathrm{d}}}$. At low wind without fetch-limitation, the strength of irradiance fluctuations can be even amplified under the influence of further developed and steeper ultra-gravity waves, thereby $\chi_{\max }$ exceeds 11 .

In the second step we investigate fully developed sea states that can occur in the open sea (some of the cases occur very rarely and are of rather theoretical interest). The applied wave spectra cover all magnitudes of ocean waves, ranging from directly wind-dependent capillaries to swell waves which are independent of local wind. Gravity waves influence the light field to much greater depths; they are the reason for (lowamplitude) irradiance variability at $80 \mathrm{~m}$ and deeper. According to the model it should be possible to observe light flashes (with $1.5 \overline{E_{\mathrm{d}}}$ ) still at $30 \mathrm{~m}$ water depth under realistic sea conditions; theoretically, light flashes can reach $75 \mathrm{~m}$. Our simulations show that the light variability at greater depths more clearly depends on the wave steepness $H / L$ of the characteristic wave of a sea state than on the wave height; the steeper a wave system, the stronger are the underwater light field fluctuations.

Acknowledgements. This work was supported by the German Research Foundation DFG (contract MA 2225/11-1). We thank Andreas Sterl for providing data form the KNMI/ERA-40 wave atlas. We also thank the reviewers and John M. Huthnance for helpful comments on the manuscript.

Edited by: J. M. Huthnance

\section{References}

Anderson, G. C.: Subsurface chlorophyll maximum in the Northeast Pacific Ocean, Limnol. Oceanogr., 14, 386-391, 1969.

Babanin, A. V.: On a wave-induced turbulence and a wavemixed upper ocean layer, Geophys. Res. Let., 33, L20605, doi:10.1029/2006GL027308, 2006.

Cox, C. and Munk, W.: Measurements of the roughness of the sea surface from photographs of the sun's glitter, J. Opt. Society Am., 44, 838-850, 1954.

Cullen, J. J.: The deep chlorophyll maximum: comparing vertical profiles of chlorophyll $a$, Can. J. Fish. Aquat. Sci., 39, 791-803, doi:10.1139/f82-108, 1982.

D’Alimonte, D., Zibordi, G., Kajiyama, T., and Cunha, J. C.: Monte Carlo code for high spatial resolution ocean color estimation, Appl. Optic, 49, 4936-4950, doi:10.1364/AO.49.004936, 2010.

Darecki, M., Stramski, D., and Sokolski, M.: Measurements of high-frequency light fluctuations induced by ocean surface waves with an underwater porcupine radiometer system, J. Geophys. Res., 116, C00H09, doi:10.1029/2011JC007338, 2011.

Deckert, R., and Michael, K. J.: Lensing effect on underwater levels of UV radiation, J. Geophys. Res., 111, C05014, doi:10.1029/2005JC003332, 2006.

Dera, J. and Stramski, D.: Maximum effects of sunlight focusing under a wind-disturbed sea surface, Oceanologia, 23, 15-42, 1986.

Donelan, M. A., Hamilton, J., and Hui, W. H.: Directional spectra of wind-generated waves, Philos. Trans. R. Soc. London, Ser. A, 315 (1534), 509-562, doi:10.1098/rsta.1985.0054, 1985.

Donelan, M. A. and Plant, W. J.: A threshold for wind-wave growth, J. Geophys. Res., 114, C07012, doi:10.1029/2008JC005238, 2009.

Elfouhaily, T., Chapron, B., Katsaros, K., and Vandemark, D.: A unified directional spectrum for long and short winddriven waves, J. Geophys. Res., 102, C7, 15781-15796, doi:10.1029/97JC00467, 1997.

Furuya, K.: Subsurface chlorophyll maximum in the tropical and subtropical western Pacific Ocean: vertical profiles of phytoplankton biomass and its relationship with chlorophyll $a$ and particulate organic carbon, Marine Biology, 107, 529-539, doi:10.1007/BF01313438, 1990.

Gege, P. and Pinnel, N.: Sources of variance of downwelling irradiance in water, Appl. Optic, 50, 2192-2203, doi:10.1364/AO.50.002192, 2011.

Gernez, P. and Antoine, D.: Field characterization of wave-induced underwater light field fluctuations, J. Geophys. Res., 114, C06025, doi:10.1029/2008JC005059, 2009.

Gernez, P., Stramski, D., and Darecki, M.: Vertical changes in the probability distribution of downwelling irradiance within the near-surface ocean under clear sky conditions, J. Geophys. Res., 116, C00H07, doi:10.1029/2011JC007156, 2011.

Hieronymi, M.: Solar radiative transfer into the ocean: A study on underwater light fluctuations due to surface waves, Ph.D. Thesis, Christian-Albrechts-Universität zu Kiel, Germany, 103 pp., 2011.

Hieronymi, M. and Macke, A.: Spatiotemporal underwater light field fluctuations in the open ocean, J. Europ. Opt. Soc. Rap. Public., 5, 10019S, 1-8, doi:10.2971/JEOS.2010.10019S, 2010.

Hieronymi, M., Macke, A., and Zielinski, O.: Modeling of waveinduced irradiance variability in the upper ocean mixed layer, Ocean Sci., 8, 103-120, doi:10.5194/os-8-103-2012, 2012. 
Huisman, J., Thi, N. N. P., Karl, D. M., and Sommeijer, B.: Reduced mixing generates oscillations and chaos in the oceanic deep chlorophyll maximum, Nature, 439, 322-325, doi:10.1038/nature04245, 2006.

ITTC: The specialist committee on waves - Final report and recommendations to the 23rd ITTC, in Proceedings of the 23rd ITTC, 2, 505-551, 2002.

Jähne, B. and Riemer, K. S.: Two-dimensional wave number spectra of small-scale water surface waves, J. Geophys. Res., 95, 1153111546, doi:10.1029/JC095iC07p11531, 1990.

Leykin, I. A. and Rozenberg, A. D.: Sea-tower measurements of wind-wave spectra in the Caspian Sea, J. Phys. Oceanogr., 14, 168-176, doi:10.1175/15200485(1984)014<0168:STMOWW>2.0.CO;2, 1984.

Longuet-Higgins, M.S.: On the skewness of sea-surface slopes, J. Phys. Oceanogr., 12, 1283-1291, doi:10.1175/15200485(1982)012<1283:OTSOSS > 2.0.CO;2, 1982.

Mobley, C. D.: Light and water: Radiative transfer in natural waters, San Diego: Academic Press, 592 pp., 1994.

Morel, A.: Are the empirical relationships describing the bio-optical properties of case 1 waters consistent and internally compatible?, J. Geophys. Res., 114, C01016, doi:10.1029/2008JC004803, 2009.

Morel, A., Gentili, B., Claustre, H., Babin, M., Bricaud, A., Ras, J., and Tieche, F.: Optical properties of the "clearest" natural waters, Limnol. Oceanogr., 52, 217-229, doi:10.4319/LO.2007.52.1.0217, 2007.

Nikolayev, V. P. and Khulapov, M. S.: Use of a nonstatistical model to explain the mechanism of underwater illumination fluctuations, Izv. Atmos Ocean. Phys., 12, 993-997, 1976.

Nikolayev, V. P., Prokopov, O. I., Rozenberg, G. V., and Shevernev, V. I.: Statistical properties of the underwater illumination, Izv. Atmos. Ocean. Phys., 8, 936-944, 1972.

Nikolayev, V. P. and Yakubenko, V. G.: On the relationship between the statistical characteristics of the underwater light field and the wave state characteristics, Izv. Atmos. Ocean. Phys., 14, 88-92, 1978.

Phillips, O. M.: Spectral and statistical properties of the equilibrium range in wind-generated gravity waves, J. Fluid Mech., 156, 505531, doi:10.1017/S0022112085002221, 1985.

Pierson, Jr., W. J. and Moskowitz, L.: A proposed spectral form for fully developed wind seas based on the similarity theory of S. A. Kitaigorodskii, J. Geophys. Res., 69, 5181-5190, doi:10.1029/JZ069i024p05181, 1964.

Preisendorfer, R. W. and Mobley, C. D.: Albedos and glitter patterns of a wind-roughened sea surface, J. Phys. Oceanogr., 16, 1293-1316, doi:10.1175/15200485(1986)016<1293:AAGPOA > 2.0.CO;2, 1986.

Queguiner, B. and Legendre, L.: Phytoplankton photosynthetic adaptation to high frequency light fluctuations simulating those induced by sea surface waves, Mar. Biol., 90, 483-491, doi:10.1007/BF00409268, 1986.

Schenck, Jr., H.: On the focusing of sunlight by ocean waves, J. Opt. Soc. Am., 47, 653-657, doi:10.1364/JOSA.47.000653, 1957.

Shen, M., Xu, Z., and Yue, D. K. P.: A model for the probability density function of downwelling irradiance under ocean waves, Optics Express, 19, 17528-17538, doi:10.1364/OE.19.017528, 2011.
Snyder, R. L. and Dera, J.: Wave-induced light field fluctuations in the Sea, J. Opt. Soc. Am., 60, 1072-1079, doi:10.1364/JOSA.60.001072, 1970.

Sterl, A. and Caires, S.: Climatology, variability and extrema of ocean waves: the web-based KNMI/ERA-40 wave atlas, Int. J. Climatol., 25, 963-977, doi:10.1002/JOC.1175, 2005.

Stramska, M. and Dickey, T. D.: Short-term variability of the underwater light field in the oligotrophic ocean in response to surface waves and clouds, Deep-Sea Res. I, 45, 1393-1410, doi:10.1016/S0967-0637(98)00020-X, 1998.

Stramski, D.: The effect of daylight diffuseness on the focusing of sunlight by sea surface waves, Oceanologia, 24, 11-27, 1986.

Stramski, D. and Dera, J.: On the mechanism for producing flashing light under a wind-disturbed water surface, Oceanologia, 25, 521, 1988.

Stramski, D. and Tegowski, J.: Effects of intermittent entrainment of air bubbles by breaking wind waves on ocean reflectance and underwater light field, J. Geophys. Res., 106, 31345-31360, doi:10.1029/2000JC000461, 2001.

Thorpe, S. A.: Bubble clouds and the dynamics of the upper ocean, Q. J. R. Meteorol. Soc., 118, 1-22, doi:10.1002/qj.49711850302, 1992.

Veal, C. J., Carmi, M., Dishon, G., Sharon, Y., Michael, K., Tchernov, D., Hoegh-Guldberg, O., and Fine, M.: Shallow-water wave lensing in coral reefs: a physical and biological case study, J. Experimental Biology, 213, 4304-4312, doi:10.1242/jeb.044941, 2010.

Walker, R. E.: Marine light field statistics, Wiley Series in Pure and Applied Optics, 675 pp., ISBN 0471310468, 1994.

Weber, V. L.: Coefficient of variation of underwater irradiance fluctuations, Radiophys. Quantum El., 53, 13-27, 2010.

Xu, Z., Yue, D. K. P., Shen, L., and Voss, K.: Patterns and statistics of in-water polarization under conditions of linear and nonlinear ocean surface waves, J. Geophys. Res., 116, C00H12, doi:10.1029/2011JC007350, 2011.

You, Y., Kattawar, G. W., Voss, K. J., Bhandari, P., Wei, J., Lewis, M., Zappa, C. J., and Schultz, H.: Polarized light field under dynamic ocean surfaces: Numerical modeling compared with measurements, J. Geophys. Res., 116, C00H05, doi:10.1029/2011JC007278, 2011.

You, Y., Stramski, D., Darecki, M., and Kattawar, G. W.: Modeling of wave-induced irradiance fluctuations at the near-surface depths in the ocean: a comparison with measurements, Appl. Opt., 49, 1041-1053, doi:10.1364/AO.49.001041, 2010.

Zaneveld, J. R. V., Boss, E., and Barnard, A.: Influence of surface waves on measured and modeled irradiance profiles, Appl. Opt., 40, 1442-1449, doi:10.1364/AO.40.001442, 2001.

Zhang, X.: Capillary-gravity and capillary waves generated in a wind tank: observations and theories, J. Fluid Mech., 289, 5182, doi:10.1017/S0022112095001236, 1995.

Zhang, X., He, M. X., Yang, Q., and Zeng, K.: Effects of wind on ocean color, IGARSS 2006, 4056-4059, doi:10.1109/IGARSS.2006.1040, 2006.

Zielinski, O., Llinás, O., Oschlies, A., and Reuter, R.: Underwater light field and its effect on one-dimensional ecosystem model at station ESTOC, north of the Canary Islands, Deep-Sea Res. II, 49, 3529-3542, doi:10.1016/S0967-0645(02)00096-6, 2002. 